\title{
NONINVASIVE BRAIN STIMULATION IN TRAUMATIC BRAIN INJURY
}

\author{
Asli Demirtas-Tatlidede ${ }^{1}$, Andrew M. Vahabzadeh-Hagh ${ }^{1}$, Montserrat Bernabeu², Jose M. \\ Tormos $^{2}$, and Alvaro Pascual-Leone ${ }^{1,2}$ \\ ${ }^{1}$ Berenson-Allen Center for Noninvasive Brain Stimulation, Beth Israel Deaconess Medical \\ Center, Harvard Medical School, Boston, MA \\ ${ }^{2}$ Guttmann University Institute for Neurorehabilitation, Universitat Autonoma de Barcelona, \\ Badalona, Spain
}

\begin{abstract}
Brain stimulation techniques have evolved in the last few decades with more novel methods capable of painless, noninvasive brain stimulation. While the number of clinical trials employing noninvasive brain stimulation continues to increase in a variety of medication-resistant neurological and psychiatric diseases, studies evaluating their diagnostic and therapeutic potential in traumatic brain injury (TBI) are largely lacking. This review introduces different techniques of noninvasive brain stimulation, which may find potential use in TBI. We cover transcranial magnetic stimulation (TMS), transcranial direct current stimulation (tDCS), low-level laser therapy (LLLT) and transcranial doppler sonography (TCD) techniques. We provide a brief overview of studies to date, discuss possible mechanisms of action, and raise a number of considerations when thinking about translating these methods to clinical use.
\end{abstract}

\section{Keywords}

Traumatic Brain Injury (TBI); Diffuse Axonal Injury (DAI); Transcranial Magnetic Stimulation (TMS); Transcranial Direct Current Stimulation (tDCS); Low-Level Laser Therapy (LLLT); Transcranial Doppler Sonography (TCD)

\footnotetext{
Copyright (C) 2011 Copyright Clearance Center, Inc. All Rights Reserved.

Corresponding Author: Alvaro Pascual-Leone, MD, PhD; Berenson-Allen Center for Noninvasive Brain Stimulation, Beth Israel Deaconess Medical Center, 330 Brookline Avenue KS-158, Boston MA 02215; Tel: +1 6176670203 ; Fax: +1 617 975 5322; apleone@bidmc.harvard.edu..

Authors' Contact Information: Asli Demirtas-Tatlidede: Berenson-Allen Center for Noninvasive Brain Stimulation, Beth Israel Deaconess Medical Center, 330 Brookline Avenue KS-158, Boston MA 02215; Tel: +1 6176670203 ; Fax: +1 617 975 5322; aslidemirtas@yahoo.com.

Andrew M. Vahabzadeh-Hagh: Berenson-Allen Center for Noninvasive Brain Stimulation, Beth Israel Deaconess Medical Center, 330 Brookline Avenue KS-158, Boston MA 02215; Tel: +1 617667 0203; Fax: +1 617975 5322; Avahabz@hst.harvard.edu. Montserrat Bernabeu: Guttmann University Institute for Neurorehabilitation, Cami Can Ruti SN 08916 Badalona, Spain; Tel: +43 93497 7700; Fax: +4393497 7715; mbernabeu@guttmann.com.

Jose $\mathbf{M}^{\mathbf{a}}$ Tormos: Guttmann University Institute for Neurorehabilitation, Cami Can Ruti SN 08916 Badalona, Spain; Tel: +43 93497 7700; Fax: +43 93497 7715; jmtormos@guttmann.com.

Alvaro Pascual-Leone: Berenson-Allen Center for Noninvasive Brain Stimulation, Beth Israel Deaconess Medical Center, 330 Brookline Avenue KS-158, Boston MA 02215; Tel: +1 617667 0203; Fax: +1 617975 5322; apleone@bidmc.harvard.edu.

Disclosure: APL serves as scientific advisor for Neosync, Neuronix, Nexstim, and Starlab. He holds IP for real-time integration of TMS with EEG and with MRI.

This is a PDF file of an unedited manuscript that has been accepted for publication. As a service to our customers we are providing this early version of the manuscript. The manuscript will undergo copyediting, typesetting, and review of the resulting proof before it is published in its final citable form. Please note that during the production process errors may be discovered which could affect the content, and all legal disclaimers that apply to the journal pertain.
} 


\section{INTRODUCTION}

Traumatic Brain Injury (TBI) occurs across the lifespan, but is most common among active and otherwise healthy teenagers and young adults. ${ }^{1,2}$ The consequences are staggering, and include a broad spectrum of cognitive, behavioral, and sensorimotor disabilities which dramatically reduce the quality of life, necessitate long-term care and create a worldwide public health problem. ${ }^{3}$ Standard rehabilitation approaches that target functional recovery following focal brain damage have limited utility in severe TBI. The characteristic dual nature of injury, which combines diffuse and focal damage, makes anatomo-clinical correlations exceptionally challenging and limits the success of conventional rehabilitation. ${ }^{4}$ Thus, there is an urgent need for improved therapeutic strategies to promote optimal functional recovery in TBI.

The neuropathophysiology of TBI is complex and involves many pathways that are incompletely characterized but may offer therapeutic targets. Unguided approaches to therapeutic innovation that do not consider known pathophysiology are unlikely to succeed. Therefore, it is worth reviewing key biochemical and molecular processes that are thought to play critical roles in the neuropathophysiology of TBI and might offer valuable targets for therapeutic intervention.

\section{NEUROPATHOPHYSIOLOGY OF TBI: DIFFERENT POTENTIAL TARGETS AT DIFFERENT TIME-POINTS FOLLOWING INSULT}

The detrimental effects of TBI evolve as a result of primary physical trauma and secondary biochemical/physiologic perturbations, both of which lead to neuronal loss and diffuse axonal injury (DAI). ${ }^{5}$

The impact of the primary physical trauma depends on the intensity and the temporal and spatial distributions of the insult. Insults of greater intensity and duration tend to result in neural necrosis while milder impacts preferentially induce apoptosis. ${ }^{6}$ Diffuse damage is most likely with inertial loading. However, even damage once deemed focal may actually be quite diffuse as demonstrated with stains specific for both neuronal axons and nerve terminals. ${ }^{7}$

Secondary biochemical perturbations involve several processes. First, excessive glutamate accumulation leads to NMDA-mediated glutamatergic excitotoxicity and neurodegeneration. ${ }^{8-11}$ Cerebral ischemia leads to a lack of oxygen and glucose delivery to neurons, resulting in reduced ATP and elevated lactate levels indicative of metabolic stress. Energy substrate deprivation impairs the ability to maintain basal ionic gradients. This leads to enhanced voltage and NMDA-dependant depolarizing postsynaptic potentials, causing neuronal and glial depolarization. NMDA receptor activation results in intracellular calcium overload, stimulating inflammation, mitochondrial dysfunction, and apoptosis. ${ }^{5,12-15}$ Elevated intracellular calcium further exacerbates and propagates metabolic stress via cortical spreading depression. ${ }^{5}$ In addition, high calcium levels may trigger calcium-induced calpain proteolysis of cytoskeletal proteins and subsequent cellular collapse ${ }^{5,6}$. Cellular destruction may also result from enhanced oxidative stress due to mitochondrial dysfunction and increased neuronal and inducible nitric oxide synthase (nNOS, iNOS), enhancing production of free radicals and lipid peroxidation. ${ }^{5,6,16-18}$ Therefore, suppression of the hyperexcitability cascade may minimize or prevent some of the disabling consequences of TBI and pose an exciting potential therapeutic target. However, excessive blockade may prevent acutely damaging mediators from later assisting in active recovery (i.e. NMDA receptor blockers, matrix metalloproteinase blockers, c-Jun N-terminal kinase pathway inhibition), ultimately resulting in therapeutic failure. ${ }^{19}$ Methods aimed at modifying TBI- 
triggered excitotoxicity that are currently in trials, including hypothermia and pharmacologic glutamate receptor antagonism ${ }^{5}$, remain unproven, are practically complex to implement, or affect the brain globally with potentially toxic side-effects.

In addition to modulation of glutamate levels, there is also evidence for the involvement of GABA, the principal inhibitory neurotransmitter in the cerebral cortex, in response to TBI. In the acute stage, transplantation of GABAergic neurons can induce recovery of sensorimotor function in rats ${ }^{23}$ while $\mathrm{GABA}_{\mathrm{A}}$ agonists can increase survival and cognitive functioning. ${ }^{24} \mathrm{GABA}$ levels were found to be elevated in MR spectroscopy performed at 24-48 hours post-TBI ${ }^{25}$ and in ventricular CSF in patients with severe TBI. ${ }^{26}$ Although increasing inhibitory function via GABA receptors seems beneficial during the acute postinjury period ${ }^{27}$, this increase may continue beyond the acute stage and hinder recovery. In rats, TBI induces long-lasting working memory deficits associated with increased GABA levels for as long as 1-month post-TBI and administration of GABA antagonists restores memory function, suggesting that lasting deficits following TBI are associated with "excess GABA-mediated inhibition". ${ }^{28}$ Critically, these deficits do not remain amenable to GABAergic treatment by 4 months post-injury. ${ }^{29}$ GABAergic terminal loss correlates with recovery following $\mathrm{TBI}^{30}$ and accompanies injury induced reorganization of the cortex. ${ }^{31}$ Therefore, in the subacute stage when GABAergic activity is excessive and promotes functional disability, increasing neuronal excitability may help counter the GABAergic tone to allow potentiation of previously unexpressed connections. ${ }^{31}$

Beyond the cascade of neurochemical responses, the nervous system reorganizes in response to injury. ${ }^{32}$ Rewiring of neural connections appears to make it possible for one part of the brain to assume the functions of a disabled region. Neuroplasticity following TBI likely includes the unmasking of previously latent synapses, synaptic alteration of receptor sensitivity, dendritic growth, collateral sprouting of new synaptic connections and arborization from neighboring undamaged neural elements. ${ }^{33,34}$ Synaptic loss, disrupting pathways after DAI, may be reestablished by dendritic growth and arborization from neighboring undamaged axons. ${ }^{35,36}$ More severe DAI, however, may lead to more concentrated and profound damage to critical neural networks. ${ }^{37}$ In this stage, recovery mechanisms operating through synaptic reorganization may not be adequate, and more complex mechanisms on the network level are likely to intervene. However, the behavioral impact of such plasticity is not necessarily adaptive and may prove to be a dead-end strategy that ultimately limits functional recovery and promotes lasting disability. ${ }^{32}$

Therefore, promotion of functional recovery following TBI appears to require differential interventions at different time-points following injury (Figure 1). In the acute phase, suppression of glutamatergic activity might be desirable and may minimize neurologic damage and disability. In the subacute phase following TBI, modulation of GABAergic inhibition might be critical to minimize functional impact and promote wellbeing. In more chronic stages, modulation of brain plasticity to suppress functionally maladaptive changes and enhance those resulting in behavioral advantages is critical to counter disability and may be used for rehabilitation of disabling sequelae.

\section{NONINVASIVE BRAIN STIMULATION TECHNIQUES IN THE CONTEXT OF TBI}

In the following section we introduce novel noninvasive stimulation methods worth considering in the context of TBI and provide a brief review of Transcranial Magnetic Stimulation, Transcranial Direct Current Stimulation, Low-Level Laser Therapy, and Transcranial Doppler Sonography techniques. 


\section{1. Transcranial Magnetic Stimulation (TMS)}

TMS is based on Faraday's principle of electromagnetic induction and features the application of rapidly changing magnetic fields to the scalp via a copper wire coil connected to a magnetic stimulator. ${ }^{38}$ These brief pulsed magnetic fields of 1-4 Tesla pass through the skull and create electric currents in discrete brain regions. ${ }^{39}$ Applied in single pulses (singlepulse TMS) appropriately delivered in time and space, the currents induced in the brain can be of sufficient magnitude to depolarize a population of neurons and evoke a certain phenomenon. ${ }^{40}$ Paired-pulse application of TMS can be used to evaluate intracortical inhibitory/excitatory circuits and cortico-cortical connectivity. ${ }^{41}$ These TMS measures have proved valuable in understanding the neurophysiologic basis of various neuropsychiatric diseases and can provide useful diagnostic information in conditions with intra- or intercortical excitability abnormalities. ${ }^{42}$

Repetitive trains of TMS (rTMS) applied to targeted brain regions can suppress or facilitate cortical processes, depending upon stimulation parameters. ${ }^{38,40}$ In most instances, continuous low frequency ( $\triangle \mathrm{Hz}$ ) rTMS decreases the excitability of the underlying cortex while bursts of intermittent high frequency ( $25 \mathrm{~Hz}$ ) rTMS enhance it. Also, a subtype of rTMS, known as Theta Burst Stimulation (TBS), incorporates very short, high frequency $(50 \mathrm{~Hz})$ trains of stimuli delivered intermittently or continuously at $5 \mathrm{~Hz} .{ }^{43,44} \mathrm{TBS}$ can induce or decrease excitability when applied in an intermittent (iTBS) or continuous (cTBS) paradigm, respectively. The fact that the modulatory effects of rTMS can outlast the duration of its application has led to the exploration of the technique as a potential treatment modality with promising results in various neuropsychiatric disorders (Figure 2A). The rTMS after-effects are influenced by the magnitude and duration of stimulation, the level of cortical excitability and the state of activity in the targeted brain region. ${ }^{45}$

Extensive neurophysiologic and neuroimaging studies in human and animal models are starting to illuminate the neurophysiology underlying rTMS effects. Overall, rTMS of a targeted brain region has been demonstrated to induce modulation distributed across corticosubcortical and corticocortical networks by means of transsynaptic spread, resulting in distant but specific changes in brain activity along functional networks. ${ }^{46-50}$ Modeling studies can provide essential information on the induced current and field distributions generated in biological tissue during TMS ${ }^{39}$ Short-term effects of TMS on brain activity appear to result from changes in neural excitability caused by shifts in the ionic equilibrium surrounding cortical neurons, reafferent feedback from targeted structures, or the storage of charge induced by stimulation. ${ }^{51}$ The prolonged after-effects are considered to result from modulation of long-term depression (LTD) and long-term potentiation (LTP) between synaptic connections, modifying neuronal plasticity. Increased expression of immediate early genes and neurotrophic effects have also been discussed as possible mechanisms. Following diffuse damage after TBI, the induction of LTP and LTD may be abnormal due to cellular injury and altered connectivity, which may ultimately account for lasting deficits. Importantly, this plastic potential might be guided using neuromodulatory strategies to improve clinical outcomes of TBI.

TMS-induced side effects primarily include transient headache, local pain, neck pain, toothache, paresthesias, transient hearing changes, transient changes in cognitive/ neuropsychological functions and syncope (possible as an epiphenomenon). ${ }^{52-54}$ The most serious adverse event related to TMS is induction of a seizure ${ }^{52-57}$ but this is a rare complication if the stimulation is applied according to the safety guidelines (See section 6 for safety considerations in TBI).

While not yet widely popular in TBI research, TMS appears to be well suited to serve as a diagnostic and prognostic factor in the case of TBI. Online or offline combinations of TMS, 
EEG and fMRI may assist in understanding the extent of injury and the mechanisms of plasticity underlying functional recovery in TBI. Its neuromodulatory potential in rehabilitation of patients with TBI also remains to be investigated. Importantly, the focality of TMS might be disadvantageous in the acute stage as diffuse damage is frequently a key component of the insult. In the subacute stage, TMS may affect potentially salvageable lesioned circuits dependent on maintaining adequate levels of arousal and avoiding activation of competitor circuits. In order to optimize the therapeutic potential of neuromodulation in promoting functional recovery in the chronic stage, extensions of insights gained from other patient populations can be translated to TBI patients with carefully characterized deficits (Section 5).

\section{2. Transcranial Direct Current Stimulation (tDCS)}

tDCS is a noninvasive technique of neuromodulation, which uses low amplitude direct current to alter neuronal firing. While the use of anodal or cathodal direct current polarization to induce changes in the firing rates of neurons was demonstrated in the 1960's, the technique has received renewed interest in recent years. Nitsche and colleagues investigated the modulatory effects of tDCS on motor cortical excitability and reported that anodal tDCS elicits prolonged increases in the cortical excitability and facilitates underlying regional activity, while cathodal stimulation shows the opposite effects. ${ }^{58,59}$ The duration of aftereffects outlasts the period of stimulation and largely depends on the duration of tDCS. Furthermore, several consecutive sessions of stimulation result in behavioral effects lasting several weeks, a particularly important feature with respect to cortical plasticity. ${ }^{60,61}$

The short-term effects of tDCS are likely elicited by a non-synaptic mechanism and result from depolarization of neuronal resting membrane, presumably caused by alterations in transmembrane proteins and electrolysis-related changes in hydrogen ions. ${ }^{58,62-64}$ Longterm effects are believed to depend on changes in NMDA receptor activation as well as neuronal hyper- and depolarization, and thus, may share similarities with LTP and LTD. ${ }^{65}$ Indeed, we have directly relevant pilot data demonstrating modulation of synaptic LTP by tDCS in a murine model (Rotenberg et al., unpublished data). In addition, a functional neuroimaging study investigating the effects of tDCS, demonstrated persistent metabolic changes in oxygen metabolism consistent with electrode location and neural network modulation. Therefore, tDCS has the potential to modify spontaneous activity and synaptic strengthening, and to modulate neurotransmitter-dependent plasticity on the network level. ${ }^{66}$

The procedure consists of a 1-2mA current applied through $35 \mathrm{~cm}^{2}$ pad electrodes placed on the scalp (Figure 2B). The low-level current flows from the positive electrode, anode, to the negative electrode, cathode, and increases the regional activity by the anode while decreasing the activity underneath the cathode. The process may be referred to as cathodal or anodal tDCS depending on the electrode placed over the region being modulated. ${ }^{67}$ Large electrode size limits the focality of stimulation, but is preferential to avoid high current densities at the skin which may cause local irritation or even burning ${ }^{64}$ It is also possible to apply the second electrode to an extracranial position (e.g. shoulder) instead of the scalp. While providing greater specificity of stimulation effects on the brain, this application may lead to quite different effects at the primary site; modeling should be considered for such novel electrode arrangements to better predict and understand the current distribution. ${ }^{68}$ Future developments (e.g. employing carrier frequencies) may help to bridge the scalp and skull and deliver the stimulating current to the brain more reliably. Even in its present form, the density of stimulation is low enough that subjects only perceive the stimulus during the rapid change in current at the onset and offset of the stimulation. Thus, from a practical point of view, it is easy to sham stimulate subjects by slowly ramping down the intensity after switch on, and ramping up before switch off. This method of sham stimulation has proven to be reliable with minimal discomfort. ${ }^{69}$ 
tDCS has been shown to enhance motor learning in healthy subjects ${ }^{70}$ and stroke patients $^{71,72}$, language in normal subjects ${ }^{73}$ and patients with aphasia ${ }^{74}$, and verbal fluency ${ }^{75}$ and verbal working memory ${ }^{76}$ in healthy subjects and patients with early Alzheimer's disease ${ }^{77}$. Furthermore, modulation on the network level allows for modulation of behaviors such as decision-making or social interactions ${ }^{78,79}$, and has been shown to have translational clinical applications in cases of impulsive behavior, addiction and depression. ${ }^{80}$ Therefore, tDCS has the potential to improve learning by modification of spontaneous activity and synaptic strengthening, and to modulate neurotransmitter-dependent plasticity on the network level. ${ }^{81}$

Several studies of the safety of tDCS have concluded that it is a painless technique for electrically stimulating the brain with almost no risk of harm. ${ }^{64,82}$ The most frequent adverse effects include moderate fatigue $(35 \%)$, mild headache $(11.8 \%)$, nausea $(2.9 \%)$ and temporary mild tingling sensation, itchiness and/or redness in the area of stimulation. While the risks are rather minimal, tDCS may also result in temporary side effects such as dizziness, disorientation, or confusion.

Overall, tDCS features a highly portable, safe, noninvasive means to modulate cortical excitability with reasonable topographic resolution and reliable experimental blinding. It can focally suppress or enhance neuronal firing following TBI, depending on the size and location of the applied electrodes, and thus may offer a promising method to minimize the damage and promote functional recovery. Cathodal tDCS may be employed to suppress the acute glutamatergic hyperexcitability following TBI. In the subacute stage, when GABAergic activity is excessive and conditions neurologic, cognitive and functional disability, anodal tDCS may increase excitability to counter these aberrant GABAergic effects. In the chronic stage, brain stimulation coupled to rehabilitation may enhance behavioral recovery, learning of new skills and cortical plasticity (Section 5). In this stage, the relative ease of use and portability of tDCS may enable modulation of plasticity via concomitant behavioral interventions such as cognitive behavioral, occupational and physical therapy. ${ }^{83-86}$

\section{3. Low-Level Laser Therapy (LLLT)}

LLLT, or photobiostimulation, is a novel method of noninvasive neural stimulation that, at specific wavelengths, can safely penetrate into the brain (Figure 3A) ${ }^{87-90}$ LLLT is thought to promote cellular survival in times of reduced energy substrate through interactions with cytochrome c oxidase to enhance oxidative phosphorylation. This interaction, believed to involve the photodissociation of nitric oxide from cytochrome c oxidase, ultimately improves mitochondrial function and increases ATP. ${ }^{91-96}$

LLLT has been shown to accelerate wound healing, reduce neurological deficit following stroke, and improve outcome in spinal cord injury. ${ }^{88,89,91,95,97}$ A study assessing the effects of LLLT following transient middle cerebral artery occlusion (MCAo) in rats demonstrated that 10 minutes of LLLT could reduce levels of neurotoxic nitric oxide synthase, eNOS, nNOS, and iNOS. Treatments also significantly increased neuroprotective TGF- $\beta 1 .{ }^{95}$ In addition, LLLT functions as a free radical scavenger, demonstrating a time-dependent decrease in the levels of reactive oxygen species while reducing expression of phospholipase $\mathrm{A}_{2} \cdot{ }^{98,99}$ Beyond LLLT's anti-inflammatory role, it may also promote neurogenesis. Oron et al. tested LLLT treatment 24 hours after permanent MCAo in rats and found significant functional improvements and increased newly formed neuronal cells in the injured hemisphere. ${ }^{89}$

Recently, LLLT was used for the first time in a rodent TBI model. LLLT was administered to mice 4 hours after injury with subsequent monitoring for 28 days using the functional 
Neurological Severity Score (NSS) in addition to lesion histology. LLLT-treated rats showed significantly reduced NSS from 5 days to 28 days post TBI with reduced lesion volume. ${ }^{89}$ Although LLLT is new to TBI research, it is currently being used in human stroke trials as an acute neuroprotective therapy. ${ }^{88,100}$ Given these early successes in stroke research and the unique properties of LLLT, its therapeutic application in TBI is a viable prospect.

\section{4. Transcranial Doppler Sonography (TCD)}

Focal ultrasound, or TCD, is not new to the field of neurological diagnostics, but the novel way in which it can be used to interact with neurobiological systems may expand the applications of this tool (Figure 3B). In the setting of TBI, TCD is used in the acute assessment of cerebral ischemia. ${ }^{102}$ Cerebral perfusion pressure (CPP), defined as the difference between the mean arterial blood pressure and intracranial pressure (ICP), has emerged as the modifiable target of intensive care of TBI patients. However, CPP is complicated by the necessity of measuring ICP, an unfavorably invasive procedure. ${ }^{102}$ Recent work demonstrated that the pulsatility index (PI; the difference in systolic and diastolic flow velocities divided by mean flow velocity) strongly correlates with ICP and $\mathrm{CPP}$ and may therefore serve as a noninvasive surrogate for these measures. ${ }^{103,104} \mathrm{TCD}$ allows one to estimate intravascular flow noninvasively using the PI. A study in patients with mild to moderate TBI showed that PI measured at time of admission was associated with neurological outcomes one week later; higher PIs associated with greater neurological deterioration as assessed by the GCS. ${ }^{104,105}$ Thus, TCD is proving to be a powerful diagnostic and prognostic tool in TBI.

More recent advances in our understanding of TCD have lead to exciting possible therapeutic roles in TBI where clot formation may result from primary injury. One application is sonothrombolysis; a technique of focal TCD applied at diagnostic frequencies alone or in combination with standard thrombolytic therapy (tPA). A recent study assessed the thrombolytic capacity of TCD using conventional transcranial color-coded sonography applied to the MCA-M1 for 1 hour in stroke patients ineligible for TPA; TCD could achieve faster recanalization rates and improved short-term outcomes in acute stroke patients. ${ }^{106} \mathrm{In}$ vitro studies have shown that US applied in combination with tPA can accelerate clot dissolution by 2.2 - to 5.5 -fold in direct proportion to the concentration of tPA. ${ }^{107,108}$ Subsequently, a multicenter collaboration tested the utility of the tPA-TCD combination in the CLOTBUST trial. They found that $83 \%$ of patients achieved recanalization with the tPA-TCD combination compared to 50\% with tPA alone. Improved efficacy with tPA-TCD is believed to result from TCD-mediated mechanical disturbance at the plasma-thrombi interface, increasing exposure of thrombi sites upon which tPA can act. ${ }^{109} \mathrm{New}$ developments in the area of therapeutic US are investigating the addition of microbubbles (air-filled microspheres) which increase focality of treatments and allow more conservative TCD settings. TCD interacts with the microbubbles to promote mechanical disruption of clots independent of tPA and may cause size expansion, oscillations, or complete disruption of the microbubbles, transmitting mechanical energy at the clot-residual flow interface to improve thrombolysis. ${ }^{109,110}$ Thus, in TBI, where thrombosis may further complicate clinical outcome, sonothrombolysis may provide a viable therapeutic option.

TCD may also have the potential to promote neuroprotection during acute TBI by increasing the local bioavailability of neuroprotective agents. TCD has been shown to transiently (i.e. hours) enhance blood brain barrier (BBB) permeability without adverse cellular effects. The mechanism is believed to be a process of stable cavitation, in which low acoustic energy causes administered microbubbles to oscillate and expand creating small eddy currents in the surrounding plasma. These currents provide shear stress on cells and large molecules to increase BBB transcellular and paracellular transport. ${ }^{110-112}$ Thus, TCD may increase the 
applicability of novel neuroprotective agents by allowing focal pharmacokinetic optimization.

Further studies have alluded to the potential of TCD as a direct means of neuroprotection. A recent study showed that low-intensity low-frequency US (LILFU) is capable of remote stimulation of mouse hippocampal slice and whole brain preparations. LILFU was shown to activate voltage-gated sodium and calcium channels triggering synaptic transmission. Additionally, stimulation of CA3 Schaffer collaterals was shown to exhibit the same kinetics and amplitudes of traditional monopolar electrical stimulation while prolonged periods of exposure (36-48 hours) did not produce aberrant membrane changes. Previous work by Rinaldi et al. demonstrated that stimulation of hippocampal slices could suppress evoked potentials in CA1 pyramidal neurons. ${ }^{113-115}$ In addition, high frequency US has been shown to elicit cortical spreading depression, a phenomenon of generalized cortical depolarization, loss of ionic gradients, and subsequent cessation of bioelectrical activity without damage. ${ }^{112}$ In the setting of TBI, these attributes of TCD may allow for suppression of neuronal activity in the acute energy deficient phase and facilitation in the subacute phase of active recovery, strengthening our therapeutic capacity against TBI.

\section{DIAGNOSTIC APPLICATIONS OF NONINVASIVE BRAIN STIMULATION IN}

\section{TBI}

Below, we review the current diagnostic evidence from TMS studies, which may offer potential neurophysiologic markers indicative of functional recovery in TBI. The monitoring of neurophysiologic impact of TMS using EEG and functional neuroimaging techniques may allow the systematic study of functional connectivity and brain-behavior relations along large-scale neural networks. ${ }^{116}$ An overview of published TMS studies on motor cortical excitability in TBI is provided in Table 1.

\subsection{Cortical Excitability}

Evidence from a limited number of studies suggests that cortical excitability in TBI is different in early and late stages of injury. Chistyakov et al. reported increased motor threshold levels (MT) and motor evoked potential (MEP) variability, prolonged central motor conduction time (CMCT) and decreased MEP/M wave ratio in mild to moderate TBI patients as early as 2 weeks after the head trauma. ${ }^{117,118}$ However, they observed that these alterations returned to normal levels within 3 months. ${ }^{118}$

A number of investigations conducted in chronic TBI patients with preserved normal motor function did not report significant differences for MEP parameters. ${ }^{34,119-124}$ However, higher MT levels, decreased MEP area, MEP variability and input-output curves were demonstrated when patients had clinically evident motor dysfunction. ${ }^{124,125}$ Moreover, alterations in the MEP parameters were more pronounced in those with severe DAI, highlighting the key influence of DAI severity on cortical excitability together with the clinical motor dysfunction (Figure 4). ${ }^{124}$

\subsection{Cortical inhibition}

Silent period (SP), a parameter reflecting intracortical inhibitory mechanisms, has been investigated in a variety of patients with TBI. De Beaumont et al. reported longer SP durations in a group of athletes who had experienced multiple concussions. ${ }^{122}$ Notably, the athletes with multiple concussions had sustained more severe concussions. The SP was significantly prolonged in such athletes but not in those with a single concussive episode. In a second study, they reported that prolongation of the SP persisted up to 40 years postconcussion and correlated with the level of bradykinesia in a group of former athletes. ${ }^{126}$ 
Chistyakov and colleagues reported a significantly longer SP in mild to moderate TBI patients when measured only at a TMS intensity of $130 \%$ of motor threshold but not at lower intensities, in contrast to MEP findings. ${ }^{127}$ The authors concluded that the mechanisms related to the MEP and SP generation might be separately affected in TBI. Recently, Bernabeu et al. reported no significant changes in SP in patients with severe TBI, while significant alterations in the MEP parameters were present. ${ }^{124}$ These studies support the evidence that excitatory and inhibitory responses probably demonstrate distinct aberrations following TBI and that the number of traumatic insults may be more critical than the severity of trauma for SP abnormalities. Further comprehensive evaluations seem requisite for clarification of intracortical inhibitiory mechanisms following TBI.

\subsection{Paired-pulse studies and connectivity measures}

Three studies employed short-interval paired-pulse TMS to assess intracortical facilitation and inhibition, and reported no significant differences in patients with mild TBI. ${ }^{119,120,122}$ Takeuchi and colleagues ${ }^{121}$ investigated whether ipsilateral silent period durations (iSP, a measure of interhemispheric connectivity that results from transcallosal modulation of activity in the unstimulated hemisphere) could detect a functional abnormality in the corpus callosum of TBI patients and reported significantly shorter iSP in patients with DAI.

\subsection{TMS, EEG and functional neuroimaging}

Using TMS, EEG and PET, Crossley and colleagues investigated the restoration of functional integrity in an old adult who suffered from severe TBI. ${ }^{128}$ TMS assessment at 12 months revealed a remarkable increase in MEP amplitudes from those recorded at 4 weeks. 18-FDG PET suggested a general increase in the metabolic rate and showed a regression in the global reduction over the year. The EEG at 4 weeks showed symmetrical slow activity with a predominance of theta frequencies while background activity at 12 months was mostly restored, consistent with the recovery of neural integrity.

Jang and colleagues assessed motor recovery mechanisms in DAI using fMRI and TMS. ${ }^{34}$ Eight patients with persistent motor weakness for $>4$ weeks post-TBI were tested after achieving stable motor recovery (mean $=6$ months). All patients but one had complete motor recovery. A hand grasp release fMRI paradigm revealed comparable activations in contralateral primary sensorimotor cortices of normal subjects and patients during affected hand movements. MEPs were not different from controls for motor threshold or amplitude, however, duration, mean latency and turns were significantly increased (Figure 4). The authors concluded that the MEP findings were likely to reflect comparable numbers of axonal fibers in the corticospinal tracts in the patient group who exhibited good recovery, and the heterogeneous characteristics of the tract were attributed to axons in the recovery process.

The combined use of TMS and fMRI may help elucidate the extent of neuropathology in severe TBI. Barba et al. ${ }^{125}$ reported a patient who presented with left hemiparesis in the absence of any detectable lesions affecting the right motor areas. TMS assessments revealed a notably higher motor threshold on the right while latency, amplitude and interhemispheric interactions were normal. Motor mapping via TMS showed reduced cortical representation and a rostral shift on the right hemisphere. Conventional fMRI did not show activations in right motor areas during a motor task paradigm whereas quantitative fMRI detected reduced activation comprising a lower number of voxels. The authors suggested that integrated investigations combining multimodal techniques should be of consideration to better clarify the relation between brain injury and clinical outcome in TBI. 


\subsection{TMS and Diffusion Tensor Imaging (DTI)}

DTI is a novel imaging technique for noninvasive in vivo visualization of white matter tracts in the brain. ${ }^{129,130}$ The degree of anisotropy (fractional anisotropy, FA) changes as a function of the degree of fiber tract organization, i.e. a reduction in FA values typically indicates histological abnormality. ${ }^{131}$ Yasokawa and colleagues hypothesized that the FA values could indicate the presence of MEPs and correlate with higher MT in patients with chronic DAI due to severe TBI. ${ }^{132}$ Indeed, they found significantly lower FA levels in the absence of MEP; lower FA levels also correlated with higher MT (Figure 4). These results provide a correlation between the neurophysiological motor dysfunction and the level of organization in the corticospinal tract following the DAI as detected by DTI.

\section{POTENTIAL THERAPEUTIC APPLICATIONS OF NONINVASIVE BRAIN STIMULATION ACCORDING TO FUNCTIONAL CONSEQUENCES OF TBI}

Here we propose future targets of intervention defined by post-TBI behavioral symptomatology rather than diagnostic categories. The selection of these functions and circuits is based on their very common and debilitating alterations following TBI and builds on insight and methodologies developed over the past decade. Given the enormous heterogeneity of the injury, implementation of individually tailored approaches using EEGand fMRI-guided TMS to modulate activity may be considered to maximize the clinical outcome in TBI.

\subsection{Hand motor function}

Hand motor dysfunction following brain damage can be improved via direct enhancement of the perilesional activity in the affected primary motor cortex or the premotor cortex in the precentral gyrus using high frequency rTMS or anodal TDCS. ${ }^{61,133}$ The alternative approach aims to decrease the excessive activation of unaffected motor cortex using low frequency rTMS or cathodal TDCS to modify the imbalance in transcallosal motor activity, which results from the loss of inhibitory projections from the damaged area and decreased use of the affected hand. Behavioral gains from rTMS/tDCS protocols may be maximized when brain stimulation is coupled with carefully designed occupational/physical therapy. ${ }^{83-86}$ In a pilot study, tDCS has been reported to enhance the effects of upper extremity robotic motor training in TBI patients with no skull defects. ${ }^{134}$

\subsection{Mood}

Modulation of dysfunctional prefrontal cortico-subcortical networks via bilateral frontal tDCS, high-frequency rTMS to the left or low-frequency rTMS to the right dorsolateral prefrontal cortex (DLPFC) results in clinically significant antidepressant effects. ${ }^{135,136}$ In the last decade, several multicenter studies have demonstrated safety and efficacy of rTMS in treatment of major depressive disorder ${ }^{137-139}$, and TMS has recently gained FDA approval for medically refractory depression. Accordingly, enhancing left DLPFC and/or inhibiting right DLPFC could be tested for post-TBI depression for reestablishment of balance in malfunctioning bihemispheric neural circuits. However, it should be noted that previously tested psychiatric populations had no comorbid brain injury, making the potential for demonstrating a positive benefit-to-risk ratio significantly better.

\subsection{Visuo-spatial functions}

Transient inhibition of the contralesional parietal region using rTMS has been reported to improve visuospatial neglect. ${ }^{140,141}$ The same paradigm might be translated to patients with neglect due to TBI. 


\subsection{Language}

Left frontotemporal cathodal tDCS and $1 \mathrm{~Hz}$ rTMS to right BA 45 has been shown to improve naming in nonfluent aphasia patients. ${ }^{74,142,143}$ These strategies, in combination with speech therapies, may be of benefit in post-traumatic expressive aphasia.

\subsection{Decision-making, working memory and executive functions}

Riskier decision-making has been reported following rTMS-induced virtual lesions of right DLPFC. ${ }^{144}$ Consequently, it seems plausible that increasing right DLPFC activity using high frequency rTMS, or neuromodulation of the DLPFC bilaterally via tDCS, may diminish decision-making impairments following TBI. ${ }^{78,144}$ Also, enhancing right or left dorsolateral prefrontal cortices may prove effective for improving working memory and/or executive dysfunctions. ${ }^{76,145-148}$

\subsection{Spasticity}

It has been reported that high frequency rTMS $(5 \mathrm{~Hz})$ to primary motor cortex increases cortical excitability as well as the excitability of spinal motor neurons to Ia afferent inhibitory input, resulting in improvements in clinical spasticity. ${ }^{149-153}$ Accordingly, postTBI spasticity may benefit from this approach.

\subsection{Pain}

Modulating sensorimotor cortical activity via TMS or tDCS can suppress pain of central origin $^{154,155}$. This potential might be explored for relief of chronic pain subsequent to trauma.

\subsection{Gait}

Repeated sessions of rTMS have been proposed as a preventive treatment for limb disuse following brain injury. ${ }^{156}$ Stimulating the leg motor cortex using high frequency rTMS may enhance gait rehabilitation in combination with gait therapy following TBI. Recently, tDCS has been reported to enhance fine motor control of the paretic ankle and improve hemiparetic gait patterns. ${ }^{157}$ In this context, one might envision coupling brain stimulation approaches with robot-assisted gait training.

It should, however, be underlined that the areas proposed here as intervention targets are based on a theoretical framework, as our understanding of brain stimulation mechanisms in TBI is yet very limited. While this framework renders noninvasive brain stimulation an attractive approach to enhance cognitive and motor functions in TBI survivors, the significant difficulties involved in demonstrating clear clinical efficacy of any form of clinical intervention in the TBI population need to be acknowledged. Hence, it is possible that following TBI, clinical heterogeneity and anatomical disconnections might necessitate modifications in the use of such neuromodulatory approaches or make these approaches fruitless. The use of correlative animal models may advance our understanding of how these modalities may act on the level of neuronal circuits and synapses following TBI, and would be particularly valuable in clarifying the rationales and the potential spectrum of translational applications before large randomized controlled trials are commenced.

\section{SAFETY CONSIDERATIONS}

The guidelines establishing the safe settings for TMS applications were published in $1998^{52}$ and revised recently ${ }^{53}$. A decade and numerous rTMS studies later, rTMS has been shown to be safe with temporary minor side effects in normal subjects if these guidelines are followed. ${ }^{54,138}$ While rTMS also appears to be a good candidate tool for neuromodulation 
following TBI, current safety guidelines have not yet been tested for this high-risk population and the risk profile of rTMS likely includes other potential side effects in patients with TBI.

The most concerning adverse event related to a possible therapeutic application of rTMS is induction of a seizure. Post-traumatic epilepsy is the most common delayed sequel of TBI with an overall incidence of about 5\% in patients with closed head injuries and $50 \%$ in those who had a compound skull fracture. ${ }^{158}$ Importantly, the interval between the head injury and the first seizure varies greatly. Although TMS-induced seizures are self-limited and do not tend to recur, this risk could bring practical implications in a seizure-prone population, especially in patients with moderate to severe TBI.

Secondly, as skull damage and fractures are common in TBI, the conductance and magnitude of the electric current being induced in cortical regions may be different. A recent tDCS modeling study highlighted that skull injuries significantly change the distribution of the current induced, and current may become concentrated over the edges of large skull defects depending on the combination of electrode configuration and nature of the defect. ${ }^{159}$ Such changes may alter the efficacy of these applications and may lead to unfavorable neurophysiologic or pathological changes. Further, the presence of a craniotomy with placement of skull plates might add another potential risk for application of these tools in TBI. ${ }^{160,161}$

Currently, there is only one case study, which performed detailed safety assessments and reported a lack of adverse events in a patient with severe TBI following application of a specific rTMS protocol over five consecutive days through six weeks. ${ }^{162}$ It is clear that the heterogeneity of TBI necessitates further extensive safety evaluation studies and definition of relative contraindications for brain stimulation in patients with TBI before a serious assessment of benefit can be undertaken. Such studies would contribute to development of safety guidelines for TBI, which may enable the safe and efficacious use of brain stimulation techniques in the rehabilitation of TBI survivors.

\section{CONCLUSION}

Different forms of noninvasive brain stimulation techniques harbor the promise of diagnostic and therapeutic utility, particularly to guide processes of cortical reorganization and enable functional restoration in TBI. Available evidence is sparse, but the present understanding about the pathophysiology of post-traumatic brain damage and the mechanisms of action of various noninvasive brain stimulation methods justifies exploration of new interventions that may forestall the functional impact of TBI. Future lines of safety research and well-designed clinical trials in TBI are warranted to ascertain the capability of noninvasive brain stimulation to promote recovery and minimize disability.

\section{Acknowledgments}

Supported in part by a BBVA Translational Research Chair in Biomedicine, a grant from the International Brain Research Foundation (IBRF), and National Institutes of Health grant K 24 RR018875 to APL, and grant PI082004 from the Instituto de Salud Carlos III. Andrew Vahabzadeh-Hagh is a Howard Hughes Medical Institute Medical Research Training Fellow.

\section{REFERENCES}

1. Sorenson S, Kraus J. Occurrence, severity, and outcomes of brain injury. J Head Trauma Rehabil. $1991 ; 6: 1-10$. 
2. Maas AI, Stocchetti N, Bullock R. Moderate and severe traumatic brain injury in adults. Lancet Neurol. 2008; 7:728-741. [PubMed: 18635021]

3. Willemse-van Son AH, Ribbers GM, Verhagen AP, Stam HJ. Prognostic factors of long-term functioning and productivity after traumatic brain injury: a systematic review of prospective cohort studies. Clin Rehabil. 2007; 21:1024-1037. [PubMed: 17984154]

4. Fontaine A, Azouvi P, Remy P, Bussel B, Samson Y. Functional anatomy of neuropsychological deficits after severe traumatic brain injury. Neurology. 1999; 53:1963-1968. [PubMed: 10599766]

5. Bramlett HM, Dietrich WD. Pathophysiology of cerebral ischemia and brain trauma: similarities and differences. J Cereb Blood Flow Metab. 2004; 24:133-150. [PubMed: 14747740]

6. Syntichaki P, Tavernarakis N. The biochemistry of neuronal necrosis: rogue biology? Nat Rev Neurosci. 2003; 4:672-684. [PubMed: 12894242]

7. Saatman K, Duhaime AC, Bullock R, Maas AIR, Valadka A, Manley GT, Workshop Scientific Team and Advisory Panel Members. Classification of Traumatic Brain Injury for Targeted Therapies. J Neurotrauma. 2008; 25:719-738. [PubMed: 18627252]

8. Faden AI, Demediuk P, Panter SS, Vink R. The role of excitatory amino acids and NMDA receptors in traumatic brain injury. Science. 1989; 244:798-800. [PubMed: 2567056]

9. Baker AJ, Moulton RJ, MacMillan VH, Shedden PM. Excitatory amino acids in cerebrospinal fluid following traumatic brain injury in humans. J Neurosurg. 1993; 79:369-372. [PubMed: 8103092]

10. Rothman SM, Olney JW. Glutamate and the pathophysiology of hypoxic--ischemic brain damage. Ann Neurol. 1986; 19:105-111. [PubMed: 2421636]

11. Yurkewicz L, Weaver J, Bullock MR, Marshall LF. The effect of the selective NMDA receptor antagonist traxoprodil in the treatment of traumatic brain injury. J Neurotrauma. 2005; 22:14281443. [PubMed: 16379581]

12. Calabresi P, Centonze D, Pisani A, Cupini L, Bernardi G. Synaptic plasticity in the ischaemic brain. Lancet Neurol. 2003; 2:622-629. [PubMed: 14505584]

13. Katsura K, Kristián T, Siesjö BK. Energy metabolism, ion homeostasis, and cell damage in the brain. Biochem Soc Trans. 1994; 22:991-996. [PubMed: 7698500]

14. Kristián T, Siesjö BK. Calcium in ischemic cell death. Stroke. 1998; 29:705-18. [PubMed: 9506616]

15. Park CK, Nehls DG, Teasdale GM, McCulloch J. Effect of the NMDA antagonist MK-801 on local cerebral blood flow in focal cerebral ischaemia in the rat. J Cereb Blood Flow Metab. 1989; 9:617-622. [PubMed: 2674169]

16. Forster C, Clark HB, Ross ME, Iadecola C. Inducible nitric oxide synthase expression in human cerebral infarcts. Acta Neuropathol. 1999; 97:215-220. [PubMed: 10090667]

17. Holtz M. Rapid expression of neuronal and inducible nitric oxide synthases during post-ischemic reperfusion in rat brain. Brain Res. 2001; 898:49-60. [PubMed: 11292448]

18. Nogawa S, Zhang F, Ross ME, Iadecola C. Cyclo-oxygenase-2 gene expression in neurons contributes to ischemic brain damage. J Neurosci. 1997; 17:2746-2755. [PubMed: 9092596]

19. Lo EH. A new penumbra: transitioning from injury into repair after stroke. Nat Med. 2008; 14:497-500. [PubMed: 18463660]

20. Raymont V, Grafman J. Cognitive neural plasticity during learning and recovery from brain damage. Prog Brain Res. 2006; 157:199-206. [PubMed: 17046672]

21. Stroemer RP, Kent TA, Hulsebosch CE. Neocortical neural sprouting, synaptogenesis, and behavioral recovery after neocortical infarction in rats. Stroke. 1995; 26:2135-2144. [PubMed: 7482662]

22. Robertson IH, Murre JM. Rehabilitation of brain damage: brain plasticity and principles of guided recovery. Psychol Bull. 1999; 125:544-575. [PubMed: 10489541]

23. Becerra GD, Tatko LM, Pak ES, Murashov AK, Hoane MR. Transplantation of GABAergic neurons but not astrocytes induces recovery of sensorimotor function in the traumatically injured brain. Behav Brain Res. 2007; 179:118-125. [PubMed: 17324477]

24. O’Dell DM, Gibson CJ, Wilson MS, DeFord SM, Hamm RJ. Positive and negative modulation of the GABA(A) receptor and outcome after traumatic brain injury in rats. Brain Res. 2000; 861:325332. [PubMed: 10760494] 
25. Pascual JM, Solivera J, Prieto R, Barrios L, López-Larrubia P, Cerdán S, Roda JM. Time course of early metabolic changes following diffuse traumatic brain injury in rats as detected by (1)H NMR spectroscopy. J Neurotrauma. 2007; 24:944-959. [PubMed: 17600512]

26. Palmer AM, Marion DW, Botscheller ML, Bowen DM, DeKosky ST. Increased transmitter amino acid concentration in human ventricular CSF after brain trauma. Neuroreport. 1994; 6:153-156. [PubMed: 7703404]

27. Shulga A, Thomas-Crusells J, Sigl T, Blaesse A, Mestres P, Meyer M, Yan Q, Kaila K, Saarma M, Rivera C, Giehl KM. Posttraumatic GABA(A)-mediated [Ca2+]i increase is essential for the induction of brain-derived neurotrophic factor-dependent survival of mature central neurons. $\mathrm{J}$ Neurosci. 2008; 28:6996-7005. [PubMed: 18596173]

28. Kobori N, Dash PK. Reversal of brain injury-induced prefrontal glutamic acid decarboxylase expression and working memory deficits by D1 receptor antagonism. J Neurosci. 2006; 26:42364246. [PubMed: 16624944]

29. Hoskison MM, Moore AN, Hu B, Orsi S, Kobori N, Dash PK. Persistent working memory dysfunction following traumatic brain injury: evidence for a time-dependent mechanism. Neuroscience. 2009; 159:483-491. [PubMed: 19167462]

30. Erb DE, Povlishock JT. Neuroplasticity following traumatic brain injury: a study of GABAergic terminal loss and recovery in the cat dorsal lateral vestibular nucleus. Exp Brain Res. 1991; 83:253-267. [PubMed: 2022238]

31. Garraghty PE, LaChica EA, Kaas JH. Injury-induced reorganization of somatosensory cortex is accompanied by reductions in GABA staining. Somatosens Mot Res. 1991; 8:347-354. [PubMed: 1667058]

32. Pascual-Leone A, Amedi A, Fregni F, Merabet LB. The plastic human brain cortex. Annu Rev Neurosci. 2005; 28:377-401. [PubMed: 16022601]

33. Blumbergs PC, Jones NR, North JB. Diffuse axonal injury in head trauma. J Neurol Neurosurg Psychiatry. 1989; 52:838-841. [PubMed: 2769276]

34. Jang SH, Cho SH, Kim YH, You SH, Kim SH, Kim O, Yang DS, Son S. Motor recovery mechanism of diffuse axonal injury: a combined study of transcranial magnetic stimulation and functional MRI. Restor Neurol Neurosci. 2005; 23:51-56. [PubMed: 15846032]

35. Povlishock JT, Katz DI. Update of neuropathology and neurological recovery after traumatic brain injury. J Head Trauma Rehabil. 2005; 20:76-94. [PubMed: 15668572]

36. Steward O. Reorganization of neural connections following CNS trauma. Principles and experimental paradigms. J Neurotrauma. 1989; 6:99-152. [PubMed: 2671393]

37. Blumbergs PC, Jones NR, North JB. Diffuse axonal injury in head trauma. J Neurol Neurosurg Psychiatry. 1989; 52:838-841. [PubMed: 2769276]

38. Kobayashi M, Pascual-Leone A. Transcranial magnetic stimulation in neurology. Lancet Neurol. 2003; 2:145-156. [PubMed: 12849236]

39. Wagner T, Valero-Cabre A, Pascual-Leone A. Noninvasive human brain stimulation. Annu Rev Biomed Eng. 2007; 9:527-565. [PubMed: 17444810]

40. Pascual-Leone, A.; Davey, N.; Rothwell, J.; Wassermann, E.; Puri, B., editors. Handbook of Transcranial Magnetic Stimulation. Oxford University Press; New York: 2002.

41. Reis J, Swayne OB, Vandermeeren Y, Camus M, Dimyan MA, Harris-Love M, Perez MA, Ragert $\mathrm{P}$, Rothwell JC, Cohen LG. Contribution of transcranial magnetic stimulation to the understanding of cortical mechanisms involved in motor control. J Physiol. 2008; 586:325-351. [PubMed: 17974592]

42. Hallett M. Transcranial magnetic stimulation: a primer. Neuron. 2007; 55:187-199. [PubMed: 17640522]

43. Huang YZ, Edwards MJ, Rounis E, Bhatia KP, Rothwell JC. Theta burst stimulation of the human motor cortex. Neuron. 2005; 45:201-206. [PubMed: 15664172]

44. Di Lazzaro V, Pilato F, Saturno E, Oliviero A, Dileone M, Mazzone P, Insola A, Tonali PA, Ranieri F, Huang YZ, Rothwell JC. Theta-burst repetitive transcranial magnetic stimulation suppresses specific excitatory circuits in the human motor cortex. J Physiol. 2005; 565:945-950. [PubMed: 15845575] 
45. Silvanto J, Pascual-Leone A. State-dependency of transcranial magnetic stimulation. Brain Topogr. 2008; 21:1-10. [PubMed: 18791818]

46. Valero-Cabré A, Pascual-Leone A. Impact of TMS on the primary motor cortex and associated spinal systems. IEEE Eng Med Biol Mag. 2005; 24:29-35.

47. Valero-Cabré A, Payne BR, Pascual-Leone A. Opposite impact on 14C-2-deoxyglucose brain metabolism following patterns of high and low frequency repetitive transcranial magnetic stimulation in the posterior parietal cortex. Exp Brain Res. 2007; 176:603-615. [PubMed: 16972076]

48. Paus T, Jech R, Thompson CJ, Comeau R, Peters T, Evans AC. Transcranial magnetic stimulation during positron emission tomography: a new method for studying connectivity of the human cerebral cortex. J Neurosci. 1997; 17:3178-3184. [PubMed: 9096152]

49. Sack AT, Kohler A, Bestmann S, Linden DE, Dechent P, Goebel R, Baudewig J. Imaging the brain activity changes underlying impaired visuospatial judgments: simultaneous FMRI, TMS, and behavioral studies. Cereb Cortex. 2007; 17:2841-2852. [PubMed: 17337745]

50. Bestmann S. The physiological basis of transcranial magnetic stimulation. Trends Cogn Sci. 2008; 12:81-83. [PubMed: 18243042]

51. Ridding MC, Rothwell JC. Is there a future for therapeutic use of transcranial magnetic stimulation? Nat Rev Neurosci. 2007; 8:559-567. [PubMed: 17565358]

52. Wassermann EM. Risk and safety of repetitive transcranial magnetic stimulation: report and suggested guidelines from the International Workshop on the Safety of Repetitive Transcranial Magnetic Stimulation, June 5-7, 1996. Electroencephalogr Clin Neurophysiol. 1998; 108:1-16. [PubMed: 9474057]

53. Rossi S, Hallett M, Rossini PM, Pascual-Leone A, The Safety of TMS Consensus Group. Safety, ethical considerations, and application guidelines for the use of transcranial magnetic stimulation in clinical practice and research. Clin Neurophysiol. 2009; 120:2008-2039. [PubMed: 19833552]

54. Machii K, Cohen D, Ramos-Estebanez C, Pascual-Leone A. Safety of rTMS to non-motor cortical areas in healthy participant and patients. Clin Neurophysiol. 2006; 117:455-471. [PubMed: 16387549]

55. Pascual-Leone A, Houser C, Reeves K. Safety of rapid-rate transcranial magnetic stimulation in normal volunteers. Electroencephalography and Clinical Neurophysiology. 1993; 89:120-130. al e. [PubMed: 7683602]

56. Wassermann E, Grafman J, Berry C, Hollnagel C, Wild K, Clark K, Hallett M. Use and safety of a new repetitive transcranial magnetic stimulator. Electroencephalography and Clinical Neurophysiology. 1996; 101:412-417. [PubMed: 8913194]

57. Chen R, Gerloff C, Wassermann E, Hallett M, Cohen LG. Safety of different inter-train intervals for repetitive transcranial magnetic stimulation and recommendations for safe ranges of stimulation parameters. Electroencephalography and Clinical Neurophysiology. 1997; 105:415421. [PubMed: 9448642]

58. Nitsche MA, Paulus W. Excitability changes induced in the human motor cortex by weak transcranial direct current stimulation. J Physiol. 2000; 527:633-639. [PubMed: 10990547]

59. Nitsche MA, Paulus W. Sustained excitability elevations induced by transcranial DC motor cortex stimulation in humans. Neurology. 2001; 57:1899-1901. [PubMed: 11723286]

60. Fregni F, Boggio PS, Santos MC, Lima M, Vieira AL, Rigonatti SP, Silva MT, Barbosa ER, Nitsche MA, Pascual-Leone A. Noninvasive cortical stimulation with transcranial direct current stimulation in Parkinson's disease. Mov Disord. 2006; 21:1693-1702. [PubMed: 16817194]

61. Boggio PS, Nunes A, Rigonatti SP, Nitsche MA, Pascual-Leone A, Fregni F. Repeated sessions of noninvasive brain DC stimulation is associated with motor function improvement in stroke patients. Restor Neurol Neurosci. 2007; 25:123-129. [PubMed: 17726271]

62. Priori A. Brain polarization in humans: a reappraisal of an old tool for prolonged non-invasive modulation of brain excitability. Clin Neurophysiol. 2003; 114:589-595. [PubMed: 12686266]

63. Purpura D, McMurtry J. Intracellular activities and evoked potential changes during polarization of motor cortex. J Neurophysiol. 1965; 28:166-185. [PubMed: 14244793] 
64. Nitsche MA, Liebetanz D, Antal A, Lang N, Tergau F, Paulus W. Modulation of cortical excitability by weak direct current stimulation technical, safety and functional aspects. Clin Neurophysiol. 2003; 56:255-276.

65. Liebetanz D, Nitsche MA, Tergau F, Paulus W. Pharmacological approach to the mechanisms of transcranial DC-stimulation-induced after effects of human motor cortex excitability. Brain. 2002; 125:2238-2247. [PubMed: 12244081]

66. Lang N, Siebner HR, Ward NS, Lee L, Nitsche MA, Paulus W, Rothwell JC, Lemon RN, Frackowiak RS. How does transcranial DC stimulation of the primary motor cortex alter regional neuronal activity in the human brain? Eur J Neurosci. 2005; 22:495-504. [PubMed: 16045502]

67. George MS, Aston-Jones G. Noninvasive techniques for probing neurocircuitry and treating illness: vagus nerve stimulation (VNS), transcranial magnetic stimulation (TMS) and transcranial direct current stimulation (tDCS). Neuropsychopharmacology. 2010; 35:301-316. [PubMed: 19693003]

68. Wagner T, Fregni F, Fecteau S, Grodzinsky A, Zahn M, Pascual-Leone A. Transcranial direct current stimulation: a computer-based human model study. Neuroimage. 2007; 35:1113-1124. [PubMed: 17337213]

69. Gandiga PC, Hummel FC, Cohen LG. Transcranial DC stimulation (tDCS): a tool for double-blind sham-controlled clinical studies in brain stimulation. Clin Neurophysiol. 2006; 117:845-850. [PubMed: 16427357]

70. Boggio PS, Castro LO, Savagim EA, Braite R, Cruz VC, Rocha RR, Rigonatti SP, Silva MT, Fregni F. Enhancement of non-dominant hand motor function by anodal transcranial direct current stimulation. Neurosci Lett. 2006; 404:232-236. [PubMed: 16808997]

71. Fregni F, Boggio PS, Mansur CG, Wagner T, Ferreira MJ, Lima MC, Rigonatti SP, Marcolin MA, Freedman SD, Nitsche MA, Pascual-Leone A. Transcranial direct current stimulation of the unaffected hemisphere in stroke patients. Neuroreport. 2005; 16:1551-1555. [PubMed: 16148743]

72. Hummel F, Cohen LG. Improvement of motor function with noninvasive cortical stimulation in a patient with chronic stroke. Neurorehabil Neural Repair. 2005; 19:14-19. [PubMed: 15673839]

73. Floel A, Cohen LG. Contribution of noninvasive cortical stimulation to the study of memory functions. Brain Res Rev. 2007; 53:250-259. [PubMed: 17023050]

74. Monti A, Cogiamanian F, Marceglia S, Ferrucci R, Mameli F, Mrakic-Sposta S, Vergari M, Zago S, Priori A. Improved naming after transcranial direct current stimulation in aphasia. J Neurol Neurosurg Psychiatry. 2008; 79:451-453. [PubMed: 18096677]

75. Iyer MB, Mattu U, Grafman J, Lomarev M, Sato S, Wassermann EM. Safety and cognitive effect of frontal DC brain polarization in healthy individuals. Neurology. 2005; 64:872-875. [PubMed: 15753425]

76. Fregni F, Boggio PS, Nitsche M, Bermpohl F, Antal A, Feredoes E, Marcolin MA, Rigonatti SP, Silva MT, Paulus W, Pascual-Leone A. Anodal transcranial direct current stimulation of prefrontal cortex enhances working memory. Exp Brain Res. 2005; 166:23-30. [PubMed: 15999258]

77. Ferrucci R, Mameli F, Guidi I, Mrakic-Sposta S, Vergari M, Marceglia S, Cogiamanian F, Barbieri S, Scarpini E, Priori A. Transcranial direct current stimulation improves recognition memory in Alzheimer disease. Neurology. 2008; 71:493-498. [PubMed: 18525028]

78. Fecteau S, Knoch D, Fregni F, Sultani N, Boggio P, Pascual-Leone A. Diminishing risk-taking behavior by modulating activity in the prefrontal cortex: a direct current stimulation study. J Neurosci. 2007; 27:12500-12505. [PubMed: 18003828]

79. Knoch D, Nitsche MA, Fischbacher U, Eisenegger C, Pascual-Leone A, Fehr E. Studying the neurobiology of social interaction with transcranial direct current stimulation--the example of punishing unfairness. Cereb Cortex. 2008; 18:1987-1990. [PubMed: 18158325]

80. Fecteau S, Fregni F, Camprodon JC, Pascual-Leone A. Neuromodulation of the addictive brain. Subst Use Misuse. 2010; 45:1766-1786. [PubMed: 20590399]

81. Rioult-Pedotti MS, Friedman D, Hess G, Donoghue JP. Strengthening of horizontal cortical connections following skill learning. Nat Neurosci. 1998; 1:230-234. [PubMed: 10195148]

82. Poreisz C, Boros K, Antal A, Paulus W. Safety aspects of transcranial direct current stimulation concerning healthy subjects and patients. Brain Res Bull. 2007; 72:208-214. [PubMed: 17452283] 
83. Edwards DJ, Krebs HI, Rykman A, Zipse J, Thickbroom GW, Mastaglia FL, Pascual-Leone A, Volpe BT. Raised corticomotor excitability of M1 forearm area following anodal tDCS is sustained during robotic wrist therapy in chronic stroke. Restor Neurol Neurosci. 2009; 27:199_ 207. [PubMed: 19531875]

84. Williams JA, Pascual-Leone A, Fregni F. Interhemispheric modulation induced by cortical stimulation and motor training. Phys Ther. 2010; 90:398-410. [PubMed: 20110339]

85. Hesse S, Werner C, Schonhardt EM, Bardeleben A, Jenrich W, Kirker SG. Combined transcranial direct current stimulation and robot-assisted arm training in subacute stroke patients: a pilot study. Restor Neurol Neurosci. 2007; 25:9-15. [PubMed: 17473391]

86. Soler MD, Kumru H, Pelayo R, Vidal J, Tormos JM, Fregni F, Navarro X, Pascual-Leone A. Effectiveness of transcranial direct current stimulation and visual illusion on neuropathic pain in spinal cord injury. Brain. 2010; 133:2565-2577. [PubMed: 20685806]

87. Ilic S, Leichliter S, Streeter J, Oron A, DeTaboada L, Oron U. Effects of Power Densities, Continuous and Pulse Frequencies, and Number of Sessions of Low-Level Laser Therapy on Intact Rat Brain. Photomed Laser Surg. 2006; 24:458-466. [PubMed: 16942425]

88. Lampl Y, Zivin JA, Fisher M, Lew R, Welin L, Dahlof B, Borenstein P, Andersson B, Perez J, Caparo C, Ilic S, Oron U. Infrared laser therapy for ischemic stroke: a new treatment strategy: results of the NeuroThera Effectiveness and Safety Trial-1 (NEST-1). Stroke. 2007; 38:18431849. [PubMed: 17463313]

89. Oron A, Oron U, Chen J, Eilam A, Zhang C, Sadeh M, Lampl Y, Streeter J, DeTaboada L, Chopp M. Low-level laser therapy applied transcranially to rats after induction of stroke significantly reduces long-term neurological deficits. Stroke. 2006; 37:2620-2624. [PubMed: 16946145]

90. Zhang Q, Ma H, Nioka S, Chance B. Study of near infrared technology for intracranial hematoma detection. J Biomed Opt. 2000; 5:206-213. [PubMed: 10938785]

91. Byrnes KR, Waynant RW, Ilev IK, Wu X, Barna L, Smith K, Heckert R, Gerst H, Anders JJ. Light promotes regeneration and functional recovery and alters the immune response after spinal cord injury. Laser Surg Med. 2005; 36:171-185.

92. Eells JT, Henry MM, Summerfelt P, Wong-Riley MT, Buchmann EV, Kane M, Whelan NT, Whelan HT. Therapeutic photobiomodulation for methanol-induced retinal toxicity. PNAS. 2003; 100:3439-3444. [PubMed: 12626762]

93. Karu T. Primary and secondary mechanisms of action of visible to near-IR radiation on cells. J Photobiochem Photobiol B. 1999; 49:1-17.

94. Karu TI, Pyatibrat LV, Afanasyeva NI. Cellular Effects of Low Power Laser Therapy Can be Mediated by Nitric Oxide. Lasers Surg Med. 2005; 36:307-314. [PubMed: 15739174]

95. Leung MC, Lo SC, Siu FK, So KF. Treatment of experimentally induced transient cerebral ischemia with low energy laser inhibits nitric oxide synthase activity and up-regulates the expression of transforming growth factor-beta 1. Lasers Surg Medn. 2002; 31:283-288.

96. Mochizuki-Oda N, Kataoka Y, Cui Y, Yamada H, Heya M, Awazu K. Effects of near-infra-red laser irradiation on adenosine triphosphate and adenosine diphosphate contents of rat brain tissue. Neurosci Lett. 2002; 323:207-210. [PubMed: 11959421]

97. Whelan HT, Smits RL Jr, Buchman EV, Whelan NT, Turner SG, Margolis DA, Cevenini V, Stinson H, Ignatius R, Martin T, Cwiklinski J, Philippi AF, Graf WR, Hodgson B, Gould L, Kane M, Chen G, Caviness J. Effect of NASA light-emitting diode irradiation on wound healing. Journal of Clinical Laser Medicine and Surgery. 2001; 19:305-314. [PubMed: 11776448]

98. Lim W, Lee S, Kim I, Chung M, Kim M, Lim H, Park J, Kim O, Choi H. The anti-inflammatory mechanism of $635 \mathrm{~nm}$ light-emitting-diode irradiation compared with existing COX inhibitors. Lasers Surg Med. 2007; 39:614-621. [PubMed: 17868110]

99. Naveh N, Bar-Ilan A, Rosner M, Schwartz M, Weissman C, Belkin M. Low-energy laser irradiation--a new measure for suppression of arachidonic acid metabolism in the optic nerve. $\mathrm{J}$ Neurosci Res. 1990; 26:386-389. [PubMed: 2168952]

100. Zivin JA, Albers GW, Bornstein N, Chippendale T, Dahlof B, Devlin T, Fisher M, Hacke W, Holt W, Ilic S, Kasner S, Lew R, Nash M, Perez J, Rymer M, Schellinger P, Schneider D, Schwab S, Veltkamp R, Walker M, Streeter J, NeuroThera Effectiveness and Safety Trial-2 Investigators. 
Effectiveness and safety of transcranial laser therapy for acute ischemic stroke. Stroke. 2009; 40:1359-1364. [PubMed: 19233936]

101. Litscher G, Wang L, Yang N, Hanselmayer R. Transorbital Doppler Assessment Of Blood Flow Velocity During Stimulation Of Acupoints Yuyao And Zanzhu. Internet J Neuromonitoring. 2000; 1:1.

102. Vespa $P$. What is the optimal threshold for cerebral perfusion pressure following traumatic brain injury. Neurosurg Focus. 2003; 15:1-5. [PubMed: 15376362]

103. Bellner J, Romner B, Reinstrup P, Kristiansson KA, Ryding E, Brandt L. Transcranial Doppler Sonography Pulsatility Index (PI) Reflects Intracranial Pressure (ICP). Surg Neurol. 2004; 62:45-51. [PubMed: 15226070]

104. Chan KH, Miller JD, Dearden NM, Andrews PJ, Midgley S. The effect of changes in cerebral perfusion pressure upon middle cerebral artery blood flow velocity and jugular bulb venous oxygen saturation after severe brain injury. J Neurosurg. 1992; 77:55-61. [PubMed: 1607972]

105. Jaffres P, Brun J, Declety P, Bosson JL, Fauvage B, Schleiermacher A, Kaddour A, Anglade D, Jacquot C, Payen JF. Transcranial Doppler to detect on admission patients at risk for neurological deterioration following mild and moderate brain trauma. Intensive Care Med. 2005; 31:785-790. [PubMed: 15834704]

106. Eggers J, Seidel G, Koch B, König IR. Sonothrombolysis in acute ischemic stroke for patients ineligible for rt-PA. Neurology. 2005; 64:1052-1054. [PubMed: 15781825]

107. Eggers J, Ossadnik S, Seidel G. Enhanced Clot Dissolution in vitro y 1.8-MHz Pulsed Ultrasound. Ultrasound in Med and Biol. 2009; 35:523-526. [PubMed: 19041172]

108. Blinc A, Francis CW, Trudnowski JL, Carstensen EL. Characterization of ultrasound-potentiated fibrinolysis in vitro. Blood. 1993; 81:2636-2643. [PubMed: 8490172]

109. Alexandrov AV. Ultrasound enhancement of fibrinolysis. Stroke. 2009; 40:S107-110. [PubMed: 19064806]

110. Meairs S, Alonso A. Ultrasound, microbubbles and the blood-brain barrier. Prog Biophys Mol Biol. 2007; 93:354-362. [PubMed: 16959303]

111. Nedelmann M, Reuter P, Walberer M, Sommer C, Alessandri B, Schiel D, Ritschel N, Kempski O, Kaps M, Mueller C, Bachmann G, Gerriets T. Detrimental effects of $60 \mathrm{kHz}$ sonothrombolysis in rats with middle cerebral artery occlusion. Ultrasound Med Biol. 2008; 34:2019-2027. [PubMed: 18723268]

112. Vykhodtseva N, McDannold N, Hynynen K. Progress and problems in the application of focused ultrasound for blood-brain barrier disruption. Ultrasonics. 2008; 48:279-296. [PubMed: 18511095]

113. Rinaldi PC, Jones JP, Reines F, Price LR. Modification by focused ultrasound pulses of electrically evoked responses from an in vitro hippocampal preparation. Brain Res. 1991; 558:36-42. [PubMed: 1933382]

114. Bachtold MR, Rinaldi PC, Jones JP, Reines F, Price LR. Focused ultrasound modifications of neural circuit activity in a mammalian brain. Ultrasound Med Biol. 1998; 24:557-565. [PubMed: 9651965]

115. Tyler WJ, Tufail Y, Finsterwald M, Tauchmann ML, Olson EJ, Majestic C. Remote excitation of neuronal circuits using low-intensity, low-frequency ultrasound. PLoS One. 2008; 3:e3511. [PubMed: 18958151]

116. Rossini PM, Rossi S. Transcranial magnetic stimulation: diagnostic, therapeutic, and research potential. Neurology. 2007; 68:484-488. [PubMed: 17296913]

117. Chistyakov AV, Soustiel JF, Hafner H, Elron M, Feinsod M. Altered excitability of the motor cortex after minor head injury revealed by transcranial magnetic stimulation. Acta Neurochir. 1998; 140:467-472.

118. Chistyakov AV, Hafner H, Soustiel JF, Trubnik M, Levy G, Feinsod M. Dissociation of somatosensory and motor evoked potentials in non-comatose patients after head injury. Clin Neurophysiol. 1999; 110:1080-1089. [PubMed: 10402095]

119. Centonze D, Palmieri MG, Boffa L, Pierantozzi M, Stanzione P, Brusa L, Marciani M, Siracusano A, Bernardi G, Caramia M. Cortical hyperexcitability in post-traumatic stress 
disorder secondary to minor accidental head trauma: a neurophysiologic study. J Psychiatry Neurosci. 2005; 30:127-132. [PubMed: 15798788]

120. Fujiki M, Hikawa T, Abe T, Ishii K, Kobayashi H. Reduced short latency afferent inhibition in diffuse axonal injury patients with memory impairment. Neurosci Lett. 2006; 405:226-230. [PubMed: 16901641]

121. Takeuchi N, Ikoma K, Chuma T, Matsuo Y. Measurement of transcallosal inhibition in traumatic brain injury by transcranial magnetic stimulation. Brain Inj. 2006; 20:991-996. [PubMed: 17046801]

122. De Beaumont L, Lassonde M, Leclerc S, Théoret H. Long-term and cumulative effects of sports concussion on motor cortex inhibition. Neurosurgery. 2007; 61:329-336. [PubMed: 17762745]

123. Moosavi SH, Ellaway PH, Catley M, Stokes MJ, Haque N. Corticospinal function in severe brain injury assessed using magnetic stimulation of the motor cortex in man. J Neurol Sci. 1999; 164:179-186. [PubMed: 10402031]

124. Bernabeu M, Demirtas-Tatlidede A, Opisso E, Lopez R, Tormos JM, Pascual-Leone A. Abnormal corticospinal excitability in traumatic diffuse axonal brain injury. J Neurotrauma. 2009; 26:2185193. [PubMed: 19604100]

125. Barba C, Formisano R, Sabatini U, Cicinelli P, Hagberg G Elisabeth, Marconi B, Ciurli P, Bianciardi M, Matteis M. Dysfunction of a structurally normal motor pathway in a brain injury patient as revealed by multimodal integrated techniques. Neurocase. 2006; 12:232-235. [PubMed: 17000593]

126. De Beaumont L, Théoret H, Mongeon D, Messier J, Leclerc S, Tremblay S, Ellemberg D, Lassonde M. Brain function decline in healthy retired athletes who sustained their last sports concussion in early adulthood. Brain. 2009; 132:695-708. [PubMed: 19176544]

127. Chistyakov AV, Soustiel JF, Hafner H, Trubnik M, Levy G, Feinsod M. Excitatory and inhibitory corticospinal responses to transcranial magnetic stimulation in patients with minor to moderate head injury. J Neurol Neurosurg Psychiatry. 2001; 70:580-587. [PubMed: 11309450]

128. Crossley M, Shiel A, Wilson B, Coleman MR, Gelling L, Fryer T, Boniface S, Pickard J. Monitoring emergence from coma following severe brain injury in an octogenarian using behavioural indicators, electrophysiological measures and metabolic studies: a demonstration of the potential for good recovery in older adults. Brain Inj. 2005; 19:729-737. [PubMed: 16195187]

129. Le Bihan D, Mangin JF, Poupon C, Clark CA, Pappata S, Molko N, Chabriat H. Diffusion tensor imaging: concepts and applications. J Magn Reson Imaging. 2001; 13:534-546. [PubMed: 11276097]

130. Pierpaoli C, Jezzard P, Basser PJ, Barnett A, Di Chiro G. Diffusion tensor imaging of human brain. Radiology. 1996; 201:637-648. [PubMed: 8939209]

131. Basser PJ, Pierpaoli C. Microstructual and physiological features of tissues elucidated by quantitative-diffusion-tensor MRI. J Magn Reson Ser B. 1996; 111:209-219. [PubMed: 8661285]

132. Yasokawa YT, Shinoda J, Okumura A, Nakayama N, Miwa K, Iwama T. Correlation between diffusion-tensor magnetic resonance imaging and motor-evoked potential in chronic severe diffuse axonal injury. J Neurotrauma. 2007; 24:163-173. [PubMed: 17263680]

133. Fregni F, Pascual-Leone A. Hand motor recovery after stroke: tuning the orchestra to improve hand motor function. Cogn Behav Neurol. 2006; 19:21-33. [PubMed: 16633016]

134. Chew, E.; Straudi, S.; Fregni, F.; Zafonte, RD.; Bonato, P. Transcranial direct current stimulation enhances the effect of upper limb functional task training in neurorehabilitation. Abstract presented at 5th World Congress of ISPRM; 2009.

135. Nitsche MA, Boggio PS, Fregni F, Pascual-Leone A. Treatment of depression with transcranial direct current stimulation (tDCS): a review. Exp Neurol. 2009; 219:14-19. [PubMed: 19348793]

136. Stern WM, Tormos JM, Press DZ, Pearlman C, Pascual-Leone A. Antidepressant effects of high and low frequency repetitive transcranial magnetic stimulation to the dorsolateral prefrontal cortex: a double-blind, randomized, placebo-controlled trial. J Neuropsychiatry Clin Neurosci. 2007; 19:179-186. [PubMed: 17431065] 
137. O'Reardon JP, Solvason HB, Janicak PG, Sampson S, Isenberg KE, Nahas Z, McDonald WM, Avery D, Fitzgerald PB, Loo C, Demitrack MA, George MS, Sackeim HA. Efficacy and safety of transcranial magnetic stimulation in the acute treatment of major depression: a multisite randomized controlled trial. Biol Psychiatry. 2007; 62:1208-1216. [PubMed: 17573044]

138. Janicak PG, O’Reardon JP, Sampson SM, Husain MM, Lisanby SH, Rado JT, Heart KL, Demitrack MA. Transcranial magnetic stimulation in the treatment of major depressive disorder: a comprehensive summary of safety experience from acute exposure, extended exposure, and during reintroduction treatment. J Clin Psychiatry. 2008; 69:222-32. [PubMed: 18232722]

139. George MS, Lisanby SH, Avery D, McDonald WM, Durkalski V, Pavlicova M, Anderson B, Nahas Z, Bulow P, Zarkowski P, Holtzheimer PE 3rd, Schwartz T, Sackeim HA. Daily left prefrontal transcranial magnetic stimulation therapy for major depressive disorder: a shamcontrolled randomized trial. Arch Gen Psychiatry. 2010; 67:507-16. [PubMed: 20439832]

140. Oliveri M, Bisiach E, Brighina F, Piazza A, La Bua V, Buffa D, Fierro B. rTMS of the unaffected hemisphere transiently reduces contralesional visuospatial hemineglect. Neurology. 2001; 57:1338-1340. [PubMed: 11591865]

141. Brighina F, Bisiach E, Oliveri M, Piazza A, La Bua V, Daniele O, Fierro B. 1 Hz repetitive transcranial magnetic stimulation of the unaffected hemisphere ameliorates contralesional visuospatial neglect in humans. Neurosci Lett. 2003; 336:131-133. [PubMed: 12499057]

142. Martin PI, Naeser MA, Theoret H, Tormos JM, Nicholas M, Kurland J, Fregni F, Seekins H, Doron K, Pascual-Leone A. Transcranial magnetic stimulation as a complementary treatment for aphasia. Semin Speech Lang. 2004; 25:181-191. [PubMed: 15118944]

143. Naeser MA, Martin PI, Nicholas M, Baker EH, Seekins H, Kobayashi M, Theoret H, Fregni F, Maria-Tormos J, Kurland J, Doron KW, Pascual-Leone A. Improved picture naming in chronic aphasia after TMS to part of right Broca's area: an open-protocol study. Brain Lang. 2005; 93:95-105. [PubMed: 15766771]

144. Knoch D, Gianotti LR, Pascual-Leone A, Treyer V, Regard M, Hohmann M, Brugger P. Disruption of right prefrontal cortex by low-frequency repetitive transcranial magnetic stimulation induces risk-taking behavior. J Neurosci. 2006; 26:6469-6472. [PubMed: 16775134]

145. Jo JM, Kim YH, Ko MH, Ohn SH, Joen B, Lee KH. Enhancing the working memory of stroke patients using tDCS. Am J Phys Med Rehabil. 2009; 88:404-409. [PubMed: 19620953]

146. Sandrini M, Rossini PM, Miniussi C. Lateralized contribution of prefrontal cortex in controlling task-irrelevant information during verbal and spatial working memory tasks: rTMS evidence. Neuropsychologia. 2008; 46:2056-2063. [PubMed: 18336847]

147. Dockery CA, Hueckel-Weng R, Birbaumer N, Plewnia C. Enhancement of planning ability by transcranial direct current stimulation. J Neurosci. 2009; 29:7271-7277. [PubMed: 19494149]

148. Vanderhasselt MA, De Raedt R, Baeken C, Leyman L, D'haenen H. The influence of rTMS over the right dorsolateral prefrontal cortex on intentional set switching. Exp Brain Res. 2006; 172:561-565. [PubMed: 16724174]

149. Valero-Cabré A, Pascual-Leone A. Impact of TMS on the primary motor cortex and associated spinal systems. IEEE Eng Med Biol Mag. 2005; 24:29-35.

150. Valero-Cabré A, Payne BR, Pascual-Leone A. Opposite impact on 14C-2-deoxyglucose brain metabolism following patterns of high and low frequency repetitive transcranial magnetic stimulation in the posterior parietal cortex. Exp Brain Res. 2007; 176:603-615. [PubMed: 16972076]

151. Centonze D, Koch G, Versace V, Mori F, Rossi S, Brusa L, Grossi K, Torelli F, Prosperetti C, Cervellino A, Marfia GA, Stanzione P, Marciani MG, Boffa L, Bernardi G. Repetitive transcranial magnetic stimulation of the motor cortex ameliorates spasticity in multiple sclerosis. Neurology. 2007; 68:1045-1050. [PubMed: 17389310]

152. Mori F, Koch G, Foti C, Bernardi G, Centonze D. The use of repetitive transcranial magnetic stimulation (rTMS) for the treatment of spasticity. Prog Brain Res. 2009; 175:429-439. [PubMed: 19660671]

153. Mori F, Codecà C, Kusayanagi H, Monteleone F, Boffa L, Rimano A, Bernardi G, Koch G, Centonze D. Effects of intermittent theta burst stimulation on spasticity in patients with multiple sclerosis. Eur J Neurol. 2010; 17:295-300. [PubMed: 19863647] 
154. Fregni F, Boggio PS, Lima MC, Ferreira MJ, Wagner T, Rigonatti SP, Castro AW, Souza DR, Riberto M, Freedman SD, Nitsche MA, Pascual-Leone A. A sham-controlled, phase II trial of transcranial direct current stimulation for the treatment of central pain in traumatic spinal cord injury. Pain. 2006; 122:197-209. [PubMed: 16564618]

155. Fregni F, Freedman S, Pascual-Leone A. Recent advances in the treatment of chronic pain with non-invasive brain stimulation techniques. Lancet Neurol. 2007; 6:188-191. [PubMed: 17239806]

156. Ricci R, Ramsey D, Johnson K, Borckardt JJ, Vallejo M, Roberts DR, George MS. A pilot feasibility study of daily rTMS to modify corticospinal excitability during lower limb immobilization. Ther Clin Risk Manag. 2008; 4:1127-1134. [PubMed: 19209293]

157. Madhavan S, Weber KA 2nd, Stinear JW. Non-invasive brain stimulation enhances fine motor control of the hemiparetic ankle: implications for rehabilitation. Exp Brain Res. DOI 10.1007/ s00221-010-2511-0.

158. Ropper, AH.; Adams, RD.; Samuels, MA.; Victor, M. Adams and Victor's Principles of neurology. 8th ed. McGraw-Hill Medical; New York: 2005. Craniocerebral trauma.

159. Datta A, Bikson M, Fregni F. Transcranial direct current stimulation in patients with skull defects and skull plates: high-resolution computational FEM study of factors altering cortical current flow. Neuroimage. 2010; 52:1268-1278. [PubMed: 20435146]

160. Rotenberg A, Harrington MG, Birnbaum DS, Madsen JR, Glass IE, Jensen FE, Pascual-Leone A. Minimal heating of titanium skull plates during $1 \mathrm{~Hz}$ repetitive transcranial magnetic stimulation. Clin Neurophysiol. 2007; 118:2536-2538. [PubMed: 17890148]

161. Rotenberg A, Pascual-Leone A. Safety of $1 \mathrm{~Hz}$ repetitive transcranial magnetic stimulation (rTMS) in patients with titanium skull plates. Clin Neurophysiol. 2009; 120:1417. [PubMed: 19560399]

162. Louise-Bender Pape T, Rosenow J, Lewis G, Ahmed G, Walker M, Guernon A, Roth H, Patil V. Repetitive TMS-Associated Neurobehavioral Gains during Coma Recovery. Brain Stimul. 2009; 2:22-35. [PubMed: 20633400] 


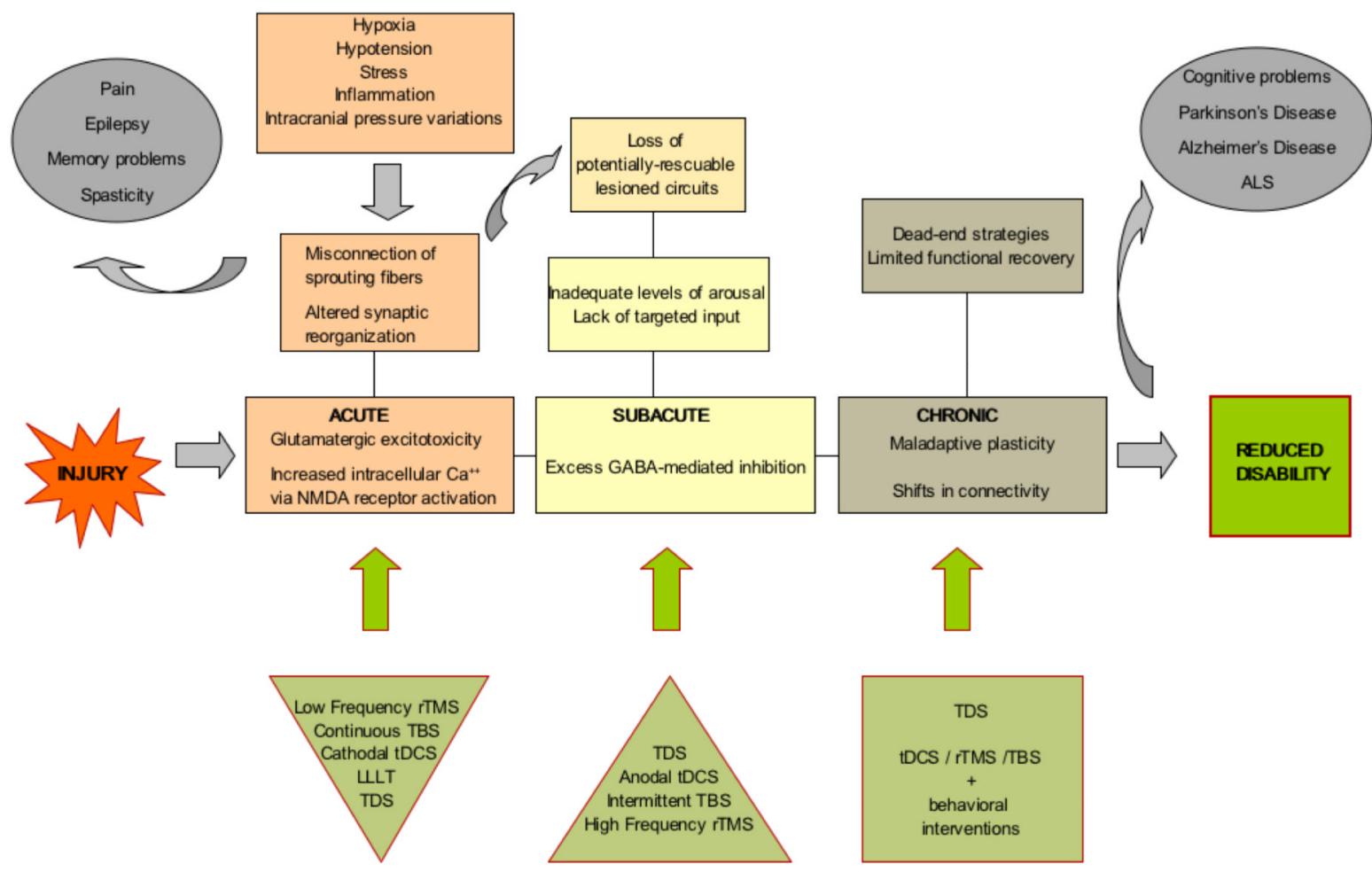

Figure 1.

After injury, compromised energy production elicits a cascade of excitatory neurotransmitters and overactivation of NMDA subclass of glutamate receptors. ${ }^{6}$ This provokes a massive increase in intracellular calcium concentration, which leads to the attenuation of mitochondrial potential and results in secondary release of calcium from the mitochondrial mass. A number of factors including stress, hemodynamics, intracranial pressure variations can contribute to the insult and disrupt natural recovery and remodeling. ${ }^{20}$ Axonal sprouting is most robust within days following $\mathrm{TBI}^{21}$ and these factors can cause sprouting fibers to lose direction and connect with the wrong terminals, leading to circuit dysfunction and functional abnormalities ${ }^{5}$ that likely contribute to longterm disabilities, such as pain, spasticity, seizures, and memory problems. Following the acute stage, the increased levels of GABA may cause excess inhibition hindering recovery. Targeted inputs and a complex environment may help maintain adequate levels of arousal for potentially rescuable circuits and hence, favor functional restoration. ${ }^{22}$ In the chronic stage, major loss of connectivity leading to lasting dysfunction will require compensatory approaches on the network level and neural plasticity may positively or negatively contribute to recovery. In the long term, cognitive problems, Parkinson's disease, amyotrophic lateral sclerosis and Alzheimer's disease may arise as a consequence of TBI ${ }^{6}$. Different forms of noninvasive brain stimulation are proposed for these stages in order to reduce disability following TBI; see relevant sections of the text for details. 

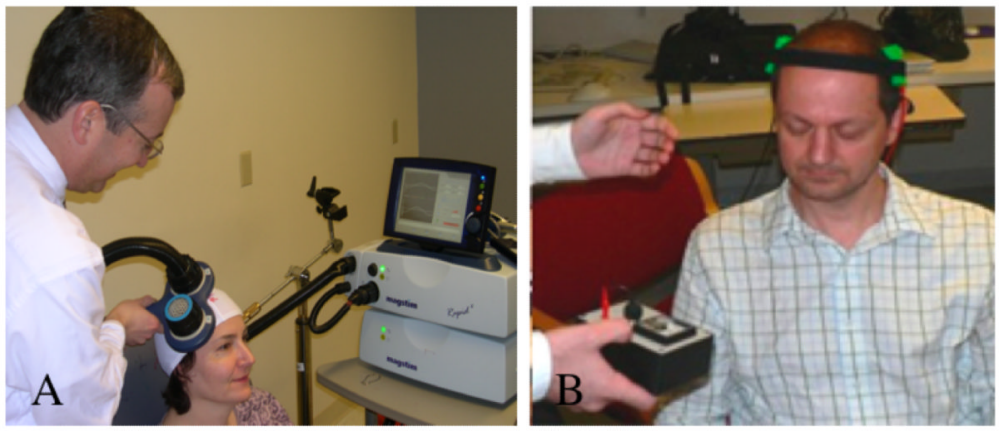

Figure 2.

(A) Therapeutic application of rTMS in a patient with depression. (B) tDCS experimental set-up. Note the saline-soaked conductive electrodes on the surface of the scalp and the small, portable size of the stimulation device (hand-held by investigator). 

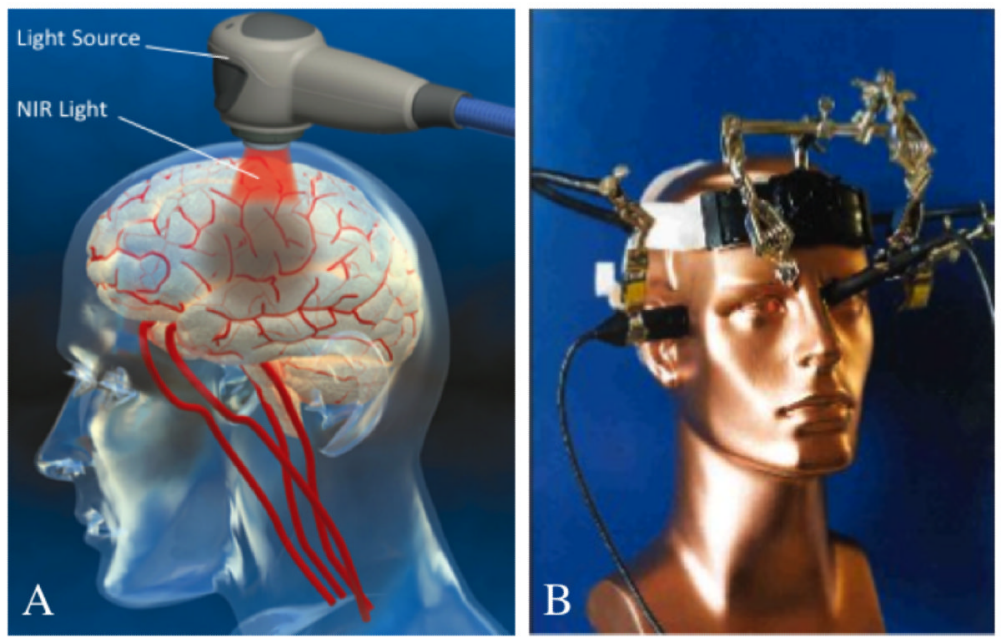

Figure 3.

(A) Illustration of light source emitting near-infrared light capable of penetrating biological tissues and therefore, capable of reaching the cerebral cortex (image courtesy of PhotoThera, Inc.). Caution: the above demonstrates the use of an investigational device - limited by Federal law to investigational use. (B) Multidirectional ultrasound device used for transcranial and/or transorbital Doppler sonography (with permission from the publisher and authors ${ }^{101}$ ). This device is no different than those currently used in the clinic to assess cerebral blood flow. Hence, the devices for diagnostic transcranial ultrasound may someday be a commonly used therapeutic tool to prevent or minimize ischemic neuronal injury, such as that which may result secondary to TBI. 


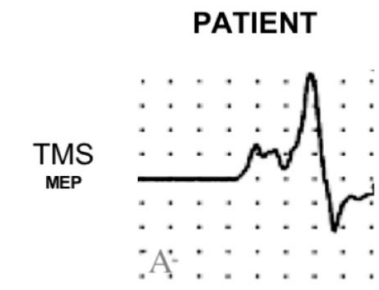

CONTROL
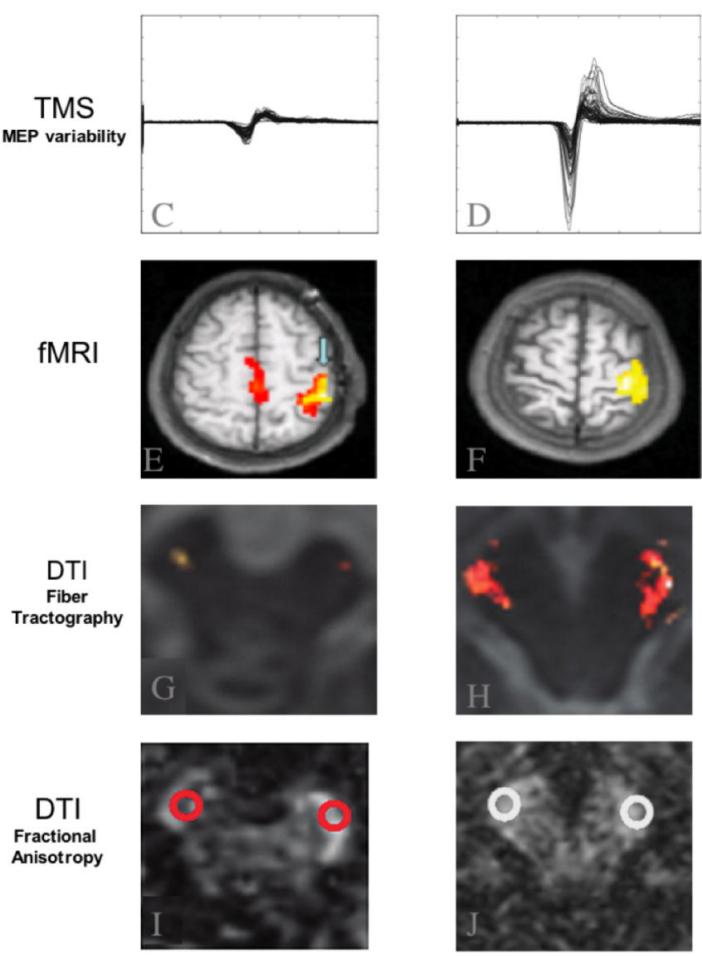

Figure 4.

MEP of (A) a patient with DAI following recovery, revealing increased duration and number of turns indicative of temporal dispersion (B) a control subject (slightly modified from ${ }^{34}$ with permission from IOS press). Superimposed MEPs demonstrate significantly decreased variability in (C) a patient with severe DAI and clinical motor dysfunction, when compared with (D) a control subject (slightly modified from ${ }^{124}$ with permission from Mary Ann Liebert, Inc. publishers). Primary motor cortex activation by hand movements of (E) a patient with DAI following recovery, (F) a control subject (slightly modified from ${ }^{34}$ with permission from IOS press). The evident mesial frontal activation in the supplementary motor area of the patient likely represents recruitment of secondary motor areas resulting from reduced capacity of primary motor regions. DTI fiber tractography of hand motor tract in $(\mathbf{G})$ a patient with DAI due to severe TBI, 18 months after trauma and (H) a control subject (modified from ${ }^{132}$ with permission from Mary Ann Liebert, Inc. publishers). Circles show the region of interests (ROI) for the FA measurements of (I) the same patient and (J) control subject (modified from ${ }^{132}$ with permission from Mary Ann Liebert, Inc. publishers). FA values were significantly lower in patients compared with controls and correlated with higher motor thresholds, presumably resulting from direct axonal damage due to DAI. 
TABLE 1

Key features of the noninvasive brain stimulation techniques

\begin{tabular}{|c|c|c|c|c|}
\hline Technique & Parameter & $\begin{array}{l}\text { Neurophysiologic } \\
\text { Effect }\end{array}$ & $\begin{array}{l}\text { Functional Effect } \\
\text { (Investigational) }\end{array}$ & Presumed Mechanisms \\
\hline \multirow[t]{2}{*}{ TMS } & $\begin{array}{l}\text { high frequency }(10-20 \\
\text { Hz), } \\
\text { intermittent theta burst }\end{array}$ & $\begin{array}{l}\text { enhance cortical } \\
\text { excitability }\end{array}$ & $\begin{array}{l}\text { improve functional } \\
\text { outcome and reduce } \\
\text { disability, } \\
\text { reduce depressive } \\
\text { symptoms, improve motor, } \\
\text { cognitive and behavioral } \\
\text { functions }\end{array}$ & $\begin{array}{l}\text { changes in neural excitability, modulation } \\
\text { of synaptic LTP; } \\
\text { may reduce excess GABA-mediated } \\
\text { inhibition, promote compensatory } \\
\text { plasticity, inhibit maladaptive plasticity in } \\
\text { TBI }\end{array}$ \\
\hline & $\begin{array}{l}\text { low frequency ( } ₫ \mathrm{~Hz} \text { ), } \\
\text { continuous theta burst }\end{array}$ & $\begin{array}{l}\text { reduce cortical } \\
\text { excitability }\end{array}$ & $\begin{array}{l}\text { improve functional } \\
\text { outcome and reduce } \\
\text { disability, } \\
\text { reduce depressive } \\
\text { symptoms, improve motor, } \\
\text { cognitive and behavioral } \\
\text { functions }\end{array}$ & $\begin{array}{l}\text { changes in neural excitability, modulation } \\
\text { of synaptic LTD; } \\
\text { may decrease glutamatergic } \\
\text { excitotoxicity, promote compensatory } \\
\text { plasticity, inhibit maladaptive plasticity in } \\
\text { TBI }\end{array}$ \\
\hline \multirow[t]{2}{*}{ tDCS } & $\begin{array}{l}\text { anodal stimulation } \\
(1-2 \mathrm{~mA})\end{array}$ & $\begin{array}{l}\text { enhance cortical } \\
\text { excitability }\end{array}$ & $\begin{array}{l}\text { improve functional } \\
\text { outcome and reduce } \\
\text { disability, } \\
\text { reduce depressive } \\
\text { symptoms, improve motor, } \\
\text { cognitive and behavioral } \\
\text { functions }\end{array}$ & $\begin{array}{l}\text { depolarization of neuronal resting } \\
\text { membrane, changes in NMDA receptor } \\
\text { activation, modulation of synaptic LTP; } \\
\text { may reduce excess GABA-mediated } \\
\text { inhibition, promote compensatory } \\
\text { plasticity, inhibit maladaptive plasticity in } \\
\text { TBI }\end{array}$ \\
\hline & $\begin{array}{l}\text { cathodal stimulation } \\
(1-2 \mathrm{~mA})\end{array}$ & $\begin{array}{l}\text { reduce cortical } \\
\text { excitability }\end{array}$ & $\begin{array}{l}\text { improve functional } \\
\text { outcome and reduce } \\
\text { disability, } \\
\text { reduce depressive } \\
\text { symptoms, improve motor, } \\
\text { cognitive and behavioral } \\
\text { functions }\end{array}$ & $\begin{array}{l}\text { depolarization of neuronal resting } \\
\text { membrane, changes in NMDA receptor } \\
\text { activation, modulation of synaptic LTD; } \\
\text { may decrease glutamatergic } \\
\text { excitotoxicity, promote compensatory } \\
\text { plasticity, inhibit maladaptive plasticity in } \\
\text { TBI }\end{array}$ \\
\hline LLLT & $660-808 \mathrm{~nm}$ & unknown & $\begin{array}{l}\text { reduce neurological deficit, } \\
\text { improve functional } \\
\text { outcome }\end{array}$ & $\begin{array}{l}\text { enhance oxidative phosphorylation, } \\
\text { improve mitochondrial function, increase } \\
\text { neuroprotective TGF- } \beta 1 \text {, } \\
\text { reduce phospholipase } \mathrm{A}_{2} \text { and reactive } \\
\text { oxygen species, promote neurogenesis }\end{array}$ \\
\hline \multirow[t]{3}{*}{ TCD } & $\begin{array}{l}\text { diagnostic frequency } \\
(1-2.2 \mathrm{Mhz})\end{array}$ & unknown & $\begin{array}{l}\text { improve short-term } \\
\text { outcomes; } \\
\text { faster recanalization rates; } \\
\text { higher local bioavailability } \\
\text { of neuroprotective agents }\end{array}$ & $\begin{array}{l}\text { mechanical disturbance at the plasma- } \\
\text { thrombi interface, } \\
\text { mechanical enhancement of BBB } \\
\text { permeability }\end{array}$ \\
\hline & $\begin{array}{l}\text { low frequency } \\
(0.44-0.67 \mathrm{Mhz})\end{array}$ & unknown & neuroprotection & $\begin{array}{l}\text { activate voltage-gated sodium and calcium } \\
\text { channels }\end{array}$ \\
\hline & $\begin{array}{l}\text { high frequency } \\
(4.89 \mathrm{Mhz})\end{array}$ & $\begin{array}{l}\text { elicit cortical } \\
\text { spreading } \\
\text { depression and } \\
\text { subsequent } \\
\text { cessation of } \\
\text { bioelectrical activity }\end{array}$ & neuroprotection & reduction in ionic gradients \\
\hline
\end{tabular}

Abbreviations: TBI: traumatic brain injury, TMS: transcranial magnetic stimulation, tDCS: transcranial direct current stimulation, LLLT: lowlevel laser therapy, TCD: transcranial doppler sonography, LTP: long-term potentiation, LTD: long-term depression, NMDA: N-Methyl-Daspartate, GABA: $\gamma$-aminobutyric acid, TGF- $\beta 1$ : transforming growth factor beta 1, BBB: Blood-brain barrier 


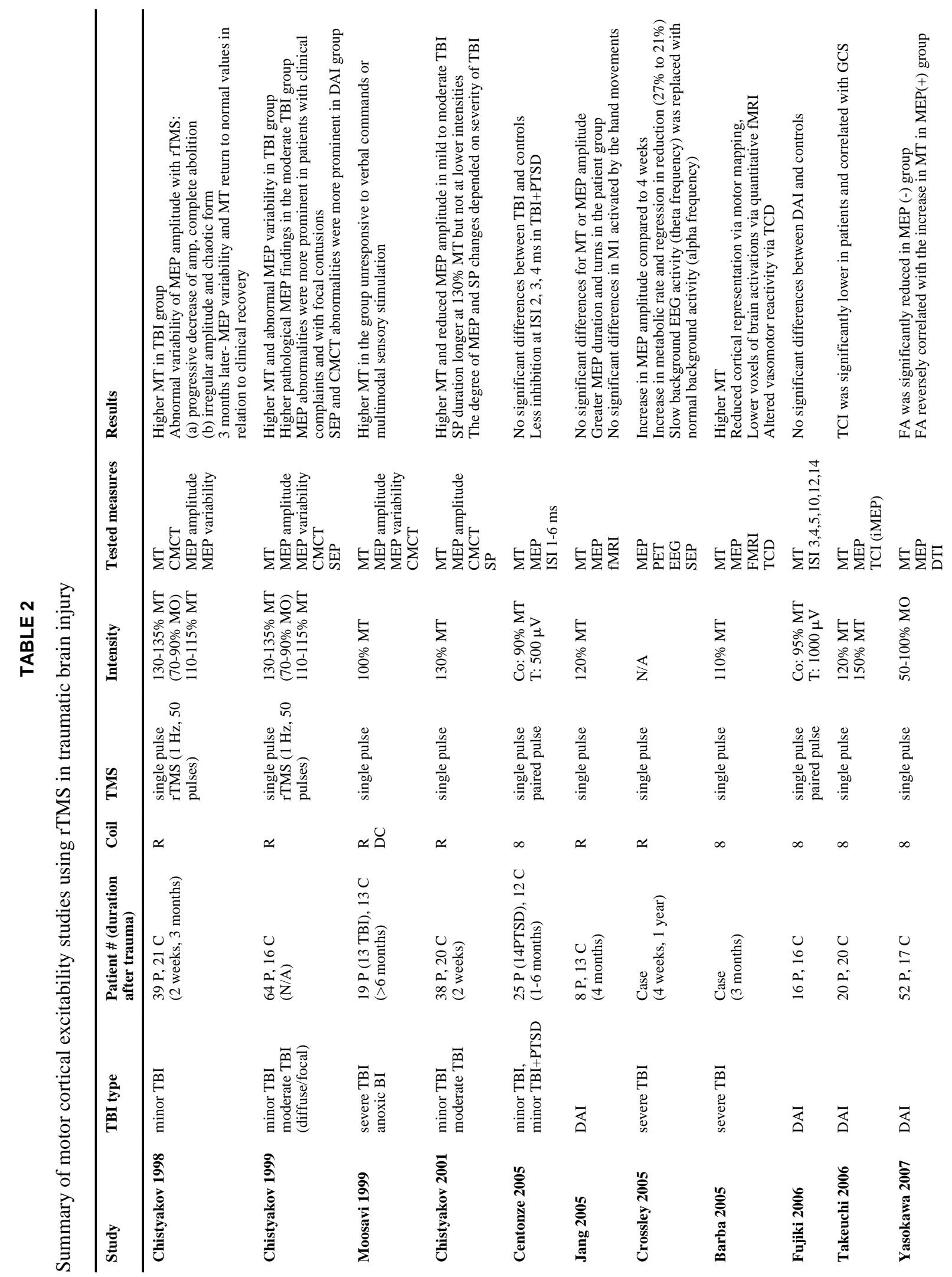

J Head Trauma Rehabil. Author manuscript; available in PMC 2013 July 01. 


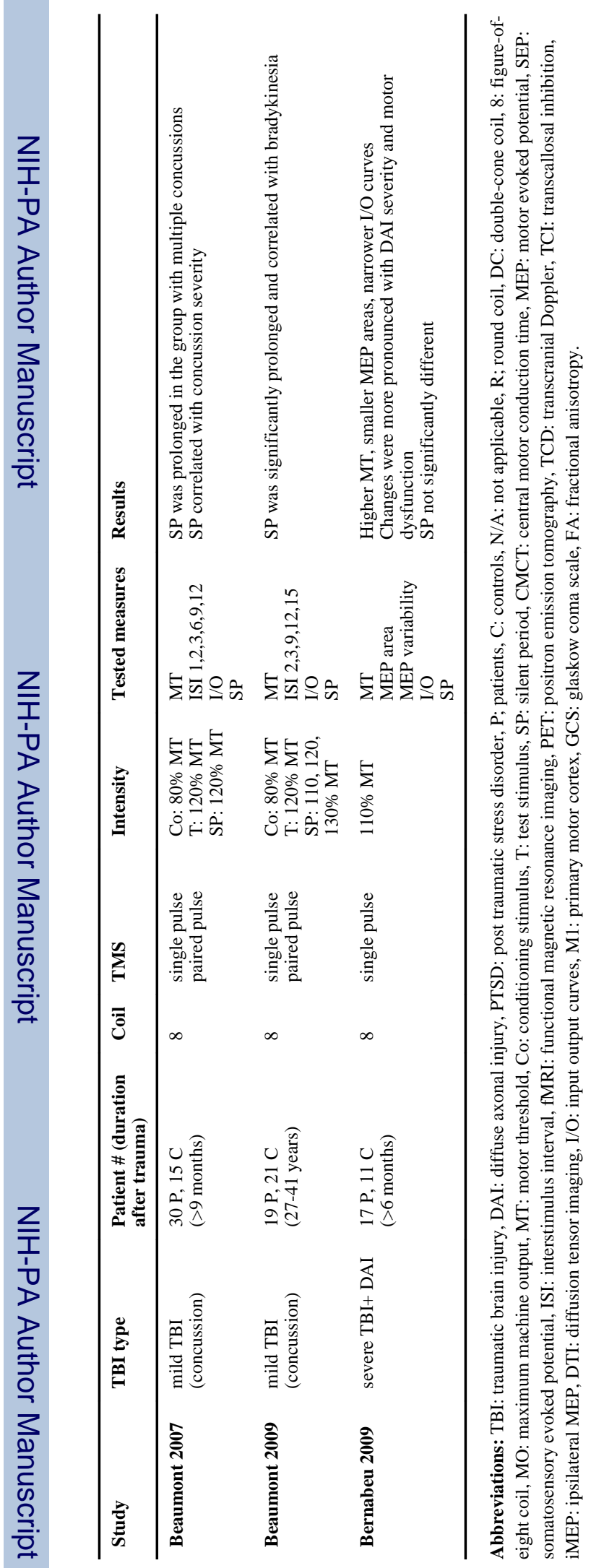

J Head Trauma Rehabil. Author manuscript; available in PMC 2013 July 01. 